\section{Glycerol and derived solvents: new sustainable reaction media for organic synthesis}

\author{
Alba E. Díaz-Álvarez, Javier Francos, Beatriz Lastra-Barreira, Pascale Crochet \\ and Victorio Cadierno*
}

Received 31st January 2011, Accepted 4th March 2011

DOI: $10.1039 / \mathrm{clcc10620a}$

The rapid growth of the biodiesel industry has led to a large surplus of its major byproduct, i.e. glycerol, for which new applications need to be found. Research efforts in this area have focused mainly on the development of processes for converting glycerol into value-added chemicals and its reforming for hydrogen production, but recently, in line with the increasing interest in the use of alternative greener solvents, an innovative way to revalorize glycerol and some of its derivatives has seen the light, i.e. their use as environmentally friendly reaction media for synthetic organic chemistry. The aim of the present Feature Article is to provide a comprehensive overview on the developments reached in this field.

\section{Introduction}

Petroleum is the main energy source in the world, but its availability is limited and the search for new renewable energy sources is of prime interest. ${ }^{1}$ Biodiesel, composed of longchain monoalkyl esters of fatty acids derived from vegetable oils or animal fats, is the most realistic alternative to effectively reduce our current dependence on fossil fuels for transportation in the short-term. ${ }^{2}$ Production of biodiesel is a relatively simple process that involves the catalytic transesterification

Departamento de Química Orgánica e Inorgánica,

Instituto Universitario de Química Organometálica "Enrique Moles"

(Unidad Asociada al CSIC), Universidad de Oviedo,

Julián Clavería 8, 33006 Oviedo, Spain.E-mail:vcm@uniovi.es;

Fax: + 34 985103446; Tel: + 34985103453 of triglycerides with a short-chain aliphatic alcohol, typically methanol, under basic conditions (Scheme 1). ${ }^{2}$ One major concern regarding the biodiesel production is the formation of glycerol (glycerine or 1,2,3-propanetriol) as a by-product ( $\sim 10 \%$ by weight). In this sense, according to recent estimates, ${ }^{3}$ world production of glycerol could have reached 1.2 million tonnes in 2010 and will grow in coming years due to the increasing demand for biodiesel. ${ }^{4}$

There are over 2000 established uses for glycerol as a high-valued starting material in the drug, food, beverage, chemicals and synthetic materials industries (see Fig. 1). It is used in cosmetics, toiletries, sweeteners, softening agents, cough syrups, surface coatings, paints and many other products. However, the large surplus of glycerol generated by the biodiesel industry has recently led to a collapse in the

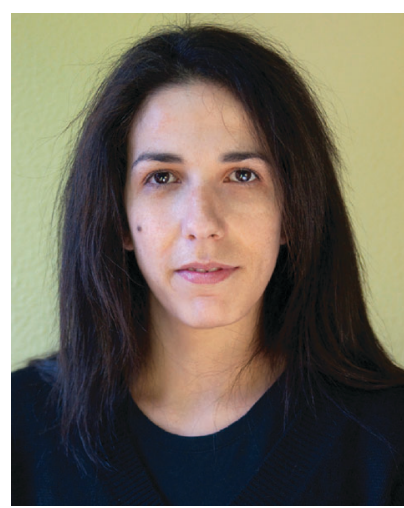

Alba E. Díaz-Álvarez
Alba E. Díaz-Álvarez studied chemistry at the University of Oviedo (Spain) and obtained his PhD degree in 2007 working on homogeneous catalysis under the supervision of Dr Pascale Crochet. After a postdoctoral stay in the group of Dr Diego Peña (University of Santiago de Compostela, Spain), developing new nanostructures based on polycyclic aromatic hydrocarbons, she returned to Oviedo in 2010 as a postdoctoral researcher. Her current work involves the development of new catalytic transformations in water and glycerol.

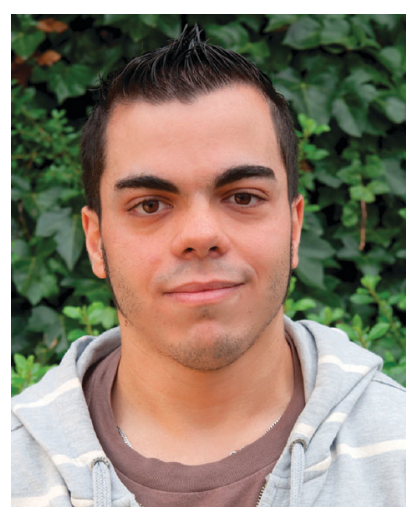

Javier Francos
Javier Francos received his $B S c$ in Chemistry from the University of Oviedo (Spain) in 2006. He is currently a PhD student working under the supervision of $\mathrm{Dr}$ V. Cadierno. In 2009 he conducted a threemonth stay in the group of Prof. J. M. J. Williams (University of Bath, UK). His research interests include the preparation of new ruthenium catalysts and their applications in green chemistry. 


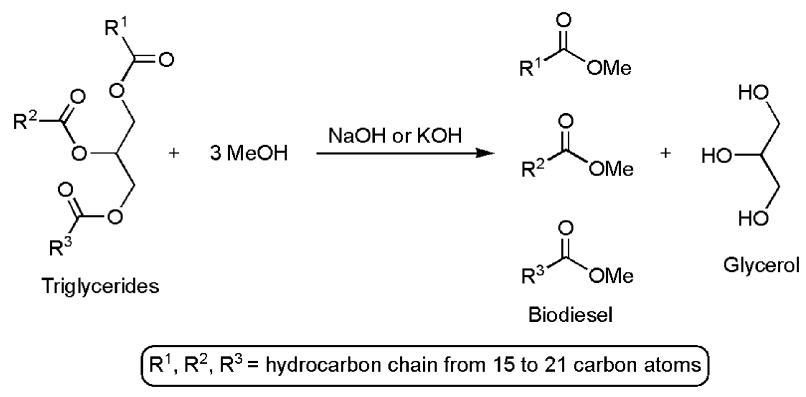

Scheme 1 Overall reaction for production of biodiesel.

prices, which has been accompanied by a growing imbalance in the supply/demand of this chemical. The current inability of the market to absorb all the glycerol produced in the biodiesel plants makes this renewable chemical become a mere waste. This scenario could have negative implications on the economic viability of many biorefineries in the near future, and also on the environment due to an improper disposal of glycerol. Consequently, new applications for this polyol as a low-cost raw material need to be developed and/or the existing ones need to be expanded. ${ }^{6}$

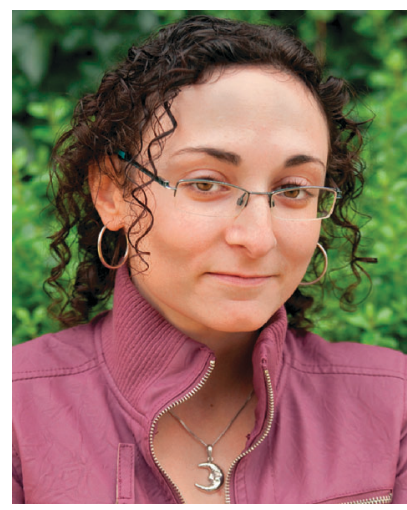

Beatriz Lastra-Barreira
Beatriz Lastra-Barreira received his BSc in Chemistry from the University of Oviedo (Spain) in 2006. She is currently a PhD student working under the supervision of Dr P. Crochet. In 2008 she conducted a two-month stay in the group of Prof. D. Bourissou (Université Paul Sabatier, France). Her thesis is focused on the design of new water-soluble ruthenium complexes and their catalytic applications.

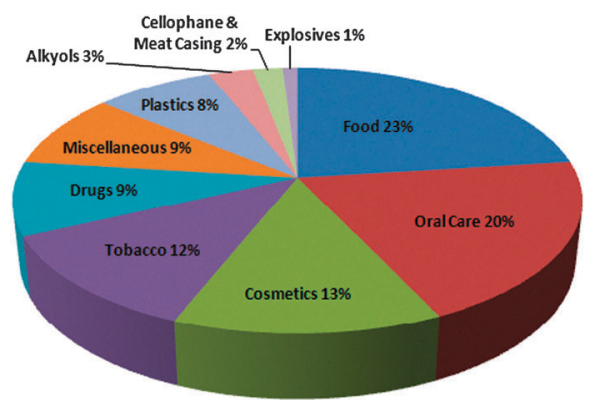

Fig. 1 The market of glycerol (industrial sectors and volumes).

Today, most of the efforts in this area are focusing on the development of procedures to convert this highly functionalized molecule into value-added chemicals that have either been previously prepared from petrochemical sources or suffered from environmental problems during their preparation. Several comprehensive review articles covering the current state-of-the-art have already appeared in the literature, and they are recommended to readers seeking a broader knowledge on this topic. ${ }^{3,6,7}$ Glycerol reforming for hydrogen production, ${ }^{8}$ and its transformation into fuel additives, ${ }^{9}$ are also extremely active areas of research. However, in order to absorb all the surpluses, new uses requiring large volumes of glycerol would be highly welcomed.

Reaction solvents are used in huge amounts and are one of the most important constituents in any chemical process. Synthetic organic chemistry is traditionally carried out in solution to facilitate the intimate contact of reactants and catalysts. Although any liquid may be potentially used as a solvent, the most widely employed in both academia and industry are the hydrocarbons (including halogenated and aromatic ones), ethers and alcohols derived from fossil fuels. However, despite the obvious usefulness of these organic solvents, problems associated with their volatility, flammability and toxicity, as well as their increasing prices, advise against their use.

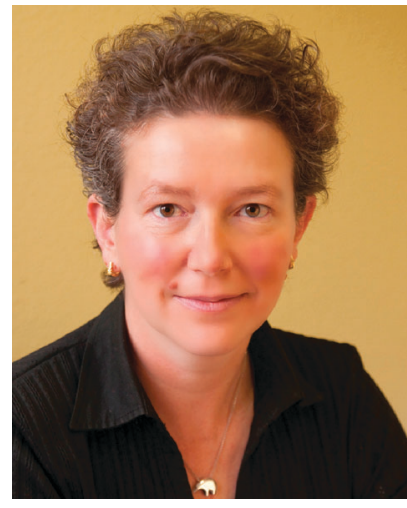

Pascale Crochet
Pascale Crochet studied chemistry at the University of Rennes I (France) and obtained her PhD in 1996 under the supervision of Prof. $P$. H. Dixneuf and $B$. Demerseman. After a twoyear post-doctoral stay in the group of Prof. M. A. Esteruelas (University of Zaragoza, Spain) and one year as an Assistant Professor at the "National High School of Physics and Chemistry" of Bordeaux (France), she moved in 1999 to the University of Oviedo where she is currently an Associate Professor of Inorganic Chemistry. Her research interests deal with the design and synthetic applications of organometallic complexes, with a particular focus on hydrosoluble ruthenium catalysts.

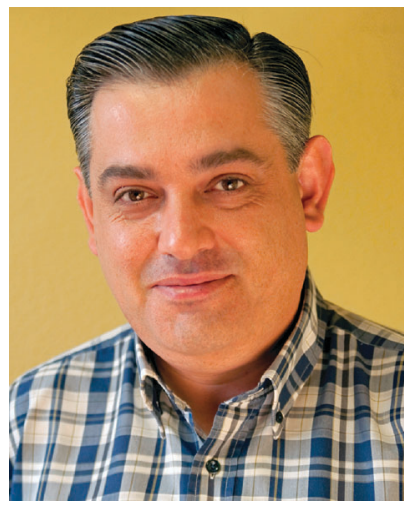

Victorio Cadierno
Victorio Cadierno studied chemistry at the University of Oviedo and obtained his PhD degree in 1996 working under the supervision of Prof. $J$. Gimeno. He then joined the group of Prof. J. P. Majoral at the LCC-CNRS (Toulouse, France) for a two-year postdoctoral stay. Thereafter, he returned to the University of Oviedo where he is currently an Associate Professor of Inorganic Chemistry. In 2002 he was awarded with the Spanish Royal Society of Chemistry (RSEQ) Young Investigator Award. His current research interests cover the development of catalytic transformations in green reaction media, being co-author of more than 110 publications. 
In recent years, safety and environmental concerns have been increasingly recognized by the chemical community worldwide, and the twelve principles of the so-called "Green Chemistry" are nowadays considered as an essential driving force in the quest for sustainable chemical processes. ${ }^{10}$ Solvents are a key component in making a process "green" and, consequently, one of the major challenges for today's chemists is to move away from the classical volatile organic solvents. ${ }^{11}$ An ideal "green" solvent should have a high boiling point, a low vapour pressure, be non-toxic, be able to dissolve a great range of compounds, be inexpensive and, of course, be recyclable. Although the universal green solvent for all situations does not exist, several alternatives have been evaluated during the last years (water, ionic liquids, supercritical fluids, perfluorinated solvents, etc.). ${ }^{12}$ Among them, water appears to be the superior choice since it satisfies the aforementioned considerations almost completely. Indeed, it is now wellaccepted that water is a reliable alternative to the petroleumbased solvents, a wide variety of highly efficient and selective synthetic protocols conducted in aqueous media being already available for practical uses. ${ }^{13}$

As water, glycerol and some of its most direct derivatives meet the requirements needed to be considered as green solvents. In fact, their use as alternative media for organic reactions has emerged as a promising new field of research, which opens a new way to revalorize this waste generated by the biodiesel industry. The aim of the present Feature Article is to provide a comprehensive overview on the developments reached in this field. In particular, after a few brief comments on the main properties of these new solvent systems, their applications in synthetic organic chemistry, catalysis and biocatalysis will be discussed in detail. At this point, we must note that a recent, non-comprehensive and complementary, article highlighting the utility of glycerol as solvent in different areas has already appeared. ${ }^{14}$ In addition, although a large number of glycerol transformations take place in the absence of any added solvent, ${ }^{6,7}$ only selected examples where glycerol is simultaneously used as a solvent and as a reagent are included here.

\section{Solvent properties of glycerol and its derivatives}

\section{Glycerol}

In pure form, glycerol is a sweet-tasting, colourless, odourless, viscous liquid which possesses a unique combination of physical and chemical properties (some key data are collected in Table 1). ${ }^{6}$ Thus, like water, glycerol is highly polar, biodegradable, immiscible with hydrocarbons and ethers (adequate therefore for biphasic catalysis and for product isolation by liquid-liquid extraction), able to form strong hydrogen bonds and to dissolve inorganic compounds (salts, acids, bases and transition metal complexes). It is also virtually non-toxic and non-flammable. Moreover, in comparison with water, it presents the advantage to dissolve organic compounds usually insoluble in water. Another interesting features of glycerol are (i) its high boiling point, which enables the development of high-temperature organic reactions in a technically easier way (the use of autoclaves or sealed tubes is
Table 1 Some physicochemical properties and toxicity data of glycerol
Melting point

Boiling point

Viscosity $\left(20^{\circ} \mathrm{C}\right)$

Vapour pressure $\left(20^{\circ} \mathrm{C}\right)$

Density $\left(20{ }^{\circ} \mathrm{C}\right)$

Flash point

Autoignition temperature

Critical temperature

Critical pressure

Dielectric constant $\left(25^{\circ} \mathrm{C}\right)$

Dipole moment $\left(30-50{ }^{\circ} \mathrm{C}\right)$

$\mathrm{LD}_{50}$ (oral-rat)

$\mathrm{LC}_{50}($ rat-1 h)
$\mathrm{LD}_{50}$ (dermal-rabbit)

\author{
$17.8^{\circ} \mathrm{C}$ \\ $290^{\circ} \mathrm{C}$ \\ $1200 \mathrm{cP}$ \\ $<1 \mathrm{~mm} \mathrm{Hg}$ \\ $1.26 \mathrm{~g} \mathrm{~cm}^{-3}$ \\ $160{ }^{\circ} \mathrm{C}$ (closed cup) \\ $400{ }^{\circ} \mathrm{C}$ \\ $492.2{ }^{\circ} \mathrm{C}$ \\ $42.5 \mathrm{~atm}$ \\ 44.38 \\ $2.68 \mathrm{D}$ \\ $12600 \mathrm{mg} \mathrm{kg}^{-1}$ \\ $>10000 \mathrm{mg} \mathrm{kg}^{-1}$ \\ $570 \mathrm{mg} \mathrm{m}^{-3}$
}

not needed) and the isolation of the final reaction products through a simple distillation process, (ii) its low vapor pressure and (iii) its high dielectric constant, all these properties facilitating its use as a suitable solvent for microwave-assisted reactions. ${ }^{15}$ However, despite all these considerations, problems associated with its high viscosity, which could provoke poor substrate diffusion in the medium, and the presence of three reactive and metal-coordinating hydroxyl groups should be taken into account prior to its utilization as solvent for a particular reaction.

For its part, crude glycerol generated in biodiesel plants is an impure material in which, depending on the feedstock and production process employed, glycerol accounts for $65-85 \mathrm{wt} \%$ of the total. ${ }^{16}$ Methanol and soaps are the major impurities contained in crude glycerol. The presence of methanol is due to the fact that biodiesel producers use excess of methanol to drive the chemical transesterification to completion, while soaps originate from the reaction of free fatty acids present in the starting materials and the base employed as a catalyst. In addition to methanol and soaps, water, inorganic salts and unreacted mono-, di- and triglycerides are also present in varying proportions. Crude glycerol usually appears as a cloudy dark-brown liquid with a high $\mathrm{pH}$ value (11-12) and, unrefined, has only a marginal value. Purifying crude glycerin is expensive and requires energy, ${ }^{6}$ so the possibility of developing large-scale synthetic processes using crude glycerol as the solvent would be highly appreciated.

\section{Glycerol-based ethers, esters and carbonates}

The drawbacks outlined above for using glycerol as a solvent can be overcome by the synthesis of a glycerol-based family of solvents whose properties can be tailored, tuned and adjusted according to the requirements of each reaction. The presence of three reactive hydroxyl groups makes glycerol an excellent platform for chemical modification, giving the opportunity to produce unlimited glycerol derivatives that can potentially be used as solvents. In this context, following classical synthetic routes García and Mayoral have prepared a family of alkyl glycerol ethers, consisting of over sixty 1,3-dialkoxy-2-propanols and 1,2,3-trialkoxypropanes, both symmetrically and unsymmetrically substituted at terminal positions, and evaluated their possible role as substitutive solvents through measurements of their physico-chemical properties (Scheme 2). ${ }^{17}$ Nearly 400 experimental data were collected for these species and 


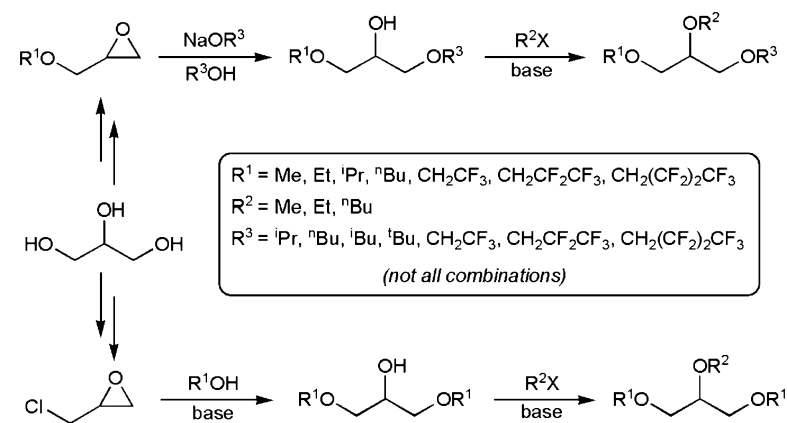

Scheme 2 Synthetic routes to symmetrical and unsymmetrical alkyl glycerol ethers.

compared with analogous properties of common organic solvents. The molecular diversity of the derivatives prepared results in significant variations of polarity, viscosity, hydrogen bond ability and hydrophobicity, while maintaining in all cases a high boiling point and low toxicity. Similarly, a variety of mono-, di-, and tri-esters are also accessible from glycerol through catalytic esterification or transesterification reactions. ${ }^{18}$ Among them, triacetin (glycerol triacetate) is the most popular representative due to its industrial applications in cosmetics and as fuel additive. As the reader will see below, this oily liquid has also found usefulness as a combined solvent and acyl donor in some catalytic and biocatalytic transformations.

Glycerol can also be easily transformed into high valueadded cyclic acetals and ketals by reaction with carbonyl compounds. ${ }^{19}$ For example, acid-catalyzed direct acetalization of glycerol with formaldehyde gives the well-known "glycerol formal", which is composed of a mixture of 5-hydroxy-1,3dioxane and 4-hydroxymethyl-1,3-dioxolane in ca. $60: 40$ ratio (Scheme 3). ${ }^{20}$ Like glycerol, glycerol formal is a viscous colorless liquid of high boiling point, which finds applications as a low-toxic solvent in different areas (injectable preparations, paints, plastifying agents, insecticide delivery systems, etc.). Note that, unlike glycerol, glycerol formal is completely miscible with ethers and acetone.

Through a related condensation reaction with acetone, solketal (2,2-dimethyl-4-hydroxymethyl-1,3-dioxolane) is also accessible. $^{21}$ As in the precedent case, the low toxicity of solketal has allowed its use as a solvent in several large-scale applications. Moreover, its polarity and hydrophobicity parameters have been determined, pointing out that its polarity lies between those of acetonitrile and ethanol, whereas its hydrophobicity is halfway between those of ethanol and 2-propanol.

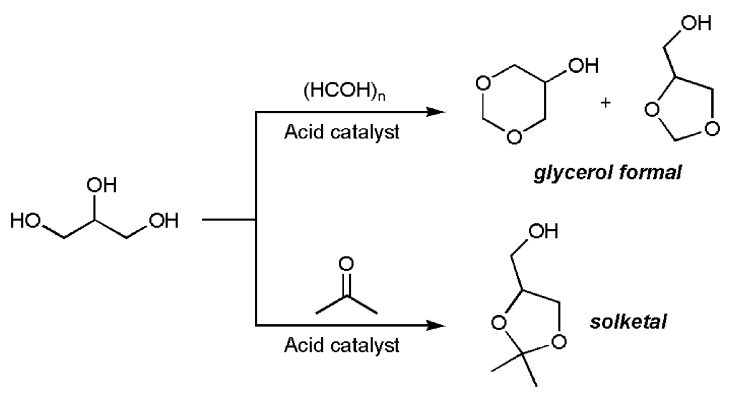

Scheme 3 Synthesis of glycerol formal and solketal.

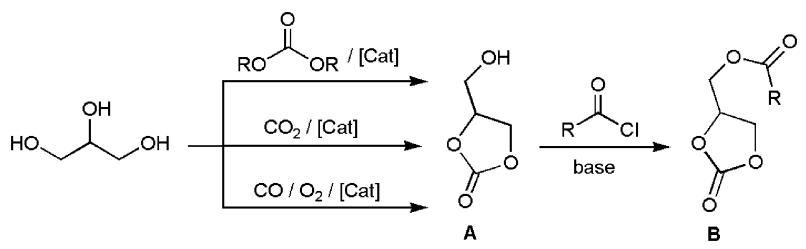

Scheme 4 Preparation and derivatization of glycerol carbonate.

The hydrogen bond ability ( $\alpha=0.81$ ) of solketal is typical for an aliphatic alcohol. ${ }^{21 c}$

Organic carbonates are becoming widely recognized as solvents for green organic synthesis due to their high biodegradability and low toxicity. ${ }^{22}$ In this context, glycerol carbonate $\mathbf{A}$ is a readily available compound that can be prepared by direct carbonation of glycerol with $\mathrm{CO}_{2},{ }^{23}$ by metal-catalyzed oxidative carbonylation of glycerol, ${ }^{24}$ or by catalytic transesterification with other carbonates (dimethyl, diethyl or propylene carbonate) or urea (Scheme 4). ${ }^{25}$ In addition, derivatization of glycerol carbonate with carboxylic acid chlorides allows the access to high-boiling carbonates $\mathbf{B}$ which are useful solvents for reactions under fine vacuum conditions at elevated temperatures. ${ }^{26}$

Despite the potential utility of all these glycerol-based ethers, esters and carbonates as solvents in organic synthesis, one should keep in mind that they contain reactive functional groups and, even if they tolerate a broad range of experimental conditions and reagents, may not be suitable solvents for any type of reactions.

\section{Glycerol-based ionic liquids and deep eutectic solvents}

As already commented, ionic liquids (ILs), salts having a melting point below $100{ }^{\circ} \mathrm{C}$, are receiving considerable attention as potential alternatives to conventional molecular organic solvents. ${ }^{27}$ An ionic liquid generally consists of a large nitrogen-containing organic cation and a smaller inorganic anion. The cation/anion asymmetry reduces the lattice energy of the crystalline structure and results in a low melting point salt. Many ionic liquids are highly polar and non-coordinating, ideal for catalytic reactions, many are immiscible with water, saturated hydrocarbons, dialkyl ethers, and a number of common organic solvents, thus providing flexibility for reaction and separation schemes. In addition, by selecting anions and cations, ILs can be easily tuned to provide a specific melting point, viscosity, volatility, density, hydrophobicity, miscibility, etc. for specific chemical systems. However, despite all these promising properties, widespread application of ILs in process chemistry is still hampered by doubts generally related to their high cost, and possible biodegradability and toxicological concerns. $^{28}$

Although their green and sustainable nature is also doubtful, some glycerol-based ILs have seen the light in recent years. In this context, Bellina and Chiappe et al. have recently described the preparation of a series of task-specific ILs based on glycerylimidazolium cations ( $\mathbf{C}$ and $\mathbf{D}$ in Fig. 2) by reaction of 1-chloropropanediol, a compound readily obtainable from glycerol, ${ }^{29}$ with the appropriate imidazolic base and subsequent alkylation of the resulting 3-(1H-imidazol-1-yl)propane-1,2diol with chloroalkanes, bromoalkanes or alkyl mesylates. ${ }^{30}$ 

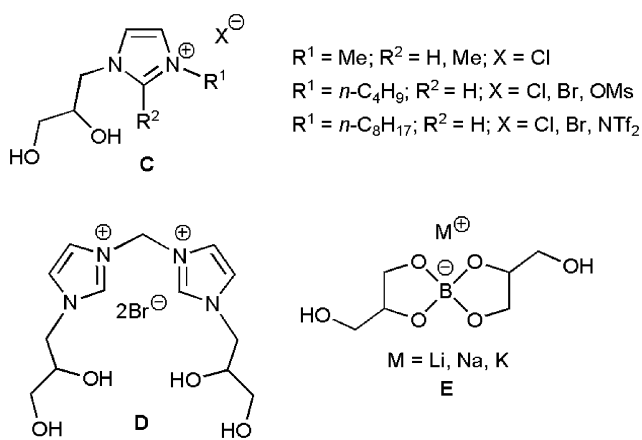

Fig. 2 Structure of some glycerol-based ionic liquids.

Alternatively, some (glycerol)borate-based ILs $\mathbf{E}$ have also been prepared by neutralization of bis(glycerol)boric acid, generated by treatment of boric acid with glycerol in refluxing toluene, with alkali hydroxides. ${ }^{31}$ All these species are potential solvents for developing selective synthetic organic reactions.

On the other hand, the so-called deep eutectic solvents (DESs) are eutectic mixtures of a solid ammonium salt and a hydrogenbond donor which, like the more classical ILs, often have melting points below room temperature, low vapor pressure, high thermal stability and are usually water-miscible. ${ }^{32}$ DESs are readily prepared from low-cost starting materials, typically by mixing choline chloride $(\mathrm{ChCl})$ or ethylammonium chloride with an organic hydrogen-bond donor such as acetamide, urea, malonic acid, etc. Compared to ILs, DESs have the advantage of being in general non-toxic and biodegradable. In addition, the solvent properties of these eutectic mixtures, in which both anions and cations as well as neutral molecules are present, differ considerably from those of ILs since, in addition to the electrostatic solvation, substrates can also establish a hydrogen-bond network with the solvent. ${ }^{33}$ Glycerol is known to form eutectic mixtures with quaternary ammonium salts, a property that has been exploited for the purification of biodiesel. ${ }^{34}$ Quite recently, the physical properties of DESs resulting from mixing choline chloride with glycerol have been quantified and it was shown that they can circumvent some of the difficulties of using glycerol as a solvent. ${ }^{35}$ Thus, by adding $\mathrm{ChCl}$ to glycerol there is a marked reduction in the viscosity (from 1200 to $400 \mathrm{cP}$ by adding $30 \mathrm{~mol} \%$ of $\mathrm{ChCl}$ ) and density (from 1.26 to $1.18 \mathrm{~g} \mathrm{~cm}^{-3}$ by adding $30 \mathrm{~mol} \%$ of $\mathrm{ChCl}$ ). This is due to the 3D intermolecular $\mathrm{H}$-bond interactions in glycerol that are broken up on addition of $\mathrm{ChCl}$, resulting in a less ordered system. Several polarity parameters $\left(E^{N}{ }_{T}, \alpha, \beta \text { and } \pi^{*}\right)^{36}$ were also measured, the data obtained suggesting that the relative polarity of these systems is similar to the classical imidazolium-based ILs.

Although the ability of DESs to serve as solvents in the field of synthetic organic chemistry has not been adequately explored, ${ }^{37}$ as the reader will see below, glycerol eutectics have already found some applications in biocatalysis.

\section{Organic synthesis without transition metals}

First examples demonstrating the utility of glycerol as solvent for synthetic organic chemistry were described by Wolfson and co-workers, who successfully accomplished the nucleophilic substitution of benzyl chloride with potassium thiocyanate,

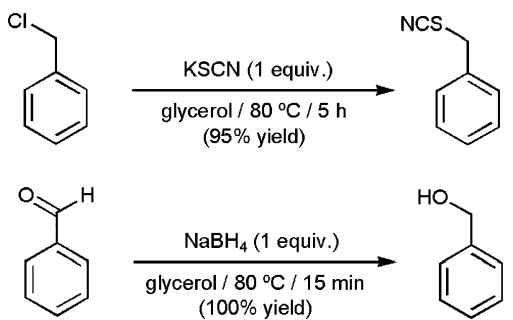

Scheme 5 Nucleophilic substitution and reduction reactions in glycerol.

and the reduction of benzaldehyde with sodium borohydride, in this "green" medium (Scheme 5). ${ }^{38}$ Reactions performed at $80{ }^{\circ} \mathrm{C}$ with stoichiometric amounts of $\mathrm{KSCN}$ and $\mathrm{NaBH}_{4}$ delivered the desired benzyl thiocyanate and alcohol, respectively, in excellent yields and short times. Further studies by the same group showed that other carbonyl compounds (aldehydes, ketones and $\beta$-ketoesters) can be selectively reduced in glycerol with $\mathrm{NaBH}_{4}{ }^{39}$ In general, reactions proceeded efficiently at room temperature with one equivalent of $\mathrm{NaBH}_{4}$, affording the final alcohols in good yields after quenching the reaction mixtures with diluted acid and extraction with diethyl ether. Interestingly, almost quantitative conversion of ethyl acetoacetate into ethyl 3-hydroxybutyrate could be reached using only 0.25 equiv. of $\mathrm{NaBH}_{4}$, i.e. the stoichiometrically correct amount of reductant based on hydride. Note that these atom-economical conditions are rarely found in the literature.

As a solvent, glycerol also allowed the reduction of benzaldehyde to toluene with hydrazine under basic conditions, via the Wolff-Kishner reaction. ${ }^{39}$ Taking advantage of the high dielectric constant and boiling point of glycerol, the process was conveniently performed using microwave irradiation heating (Scheme 6).

After these pioneering works, many other useful synthetic protocols in glycerol have been developed. Thus, Gu and Jérôme have demonstrated that glycerol is an efficient promoting medium for the catalyst-free aza-Michael addition of amines to $\alpha, \beta$-unsaturated carbonyl compounds and nitriles (Scheme 7). ${ }^{40}$ Reactions performed at $80-100{ }^{\circ} \mathrm{C}$ afforded the corresponding mono-adducts 1-2 in good yields after extraction of the crude mixtures with ethyl acetate, and subsequent chromatographic work-up. In addition, the recovered glycerol phase could be reused, with the yields obtained after three consecutive runs being comparable to those reached in fresh glycerol.

Remarkably, classical organic solvents, such as toluene, DMF, DMSO or 1,2-dichloroethane, were completely ineffective for these reactions, and only trace amounts of 1-2 were

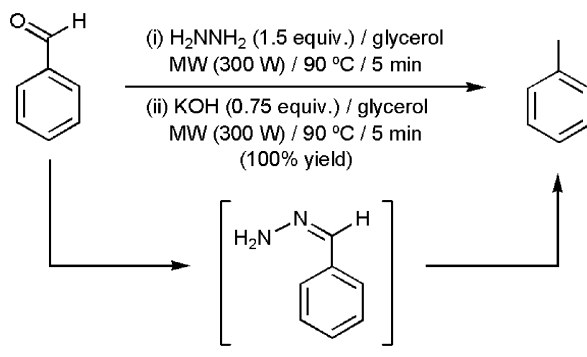

Scheme 6 Wolff-Kishner reduction of benzaldehyde in glycerol. 
<smiles>[R]N[NH2+]C(=C)C(=O)OCC</smiles>

$R^{1}=H ; R^{2}=P h ; R^{3}=H ; R^{4}={ }^{n} B u, C y$

$R^{1}=H ; R^{2}=4-C_{6} H_{4} M e ; R^{3}=H ; R^{4}={ }^{n} B u, C y$

$R^{1}=M e ; R^{2}=B n ; R^{3}=M e ; R^{4}=B n$

$R^{1}=R^{2}=B n ; R^{3}=H ; R^{4}={ }^{n} B u$

$R^{1} R^{2} N H=1,2,3,4$-tetrahydroisoquinoline; $R^{3}=M e ; R^{4}=B n$
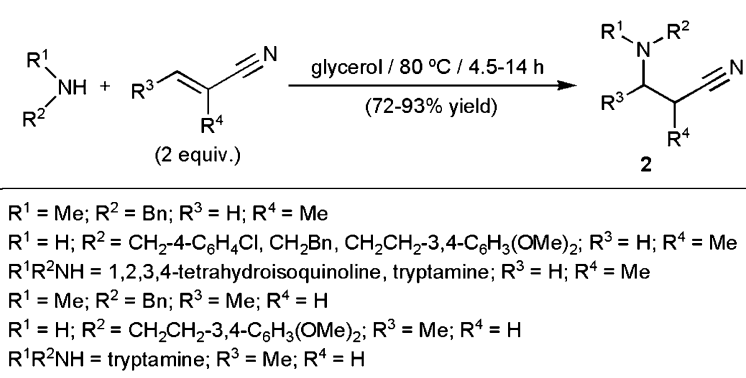

Scheme 7 Catalyst-free aza-Michael reactions in glycerol.

formed in water or under solvent-free conditions. A similar trend was also observed when studying the Michael addition of indoles to $\beta$-nitrostyrene and 3-buten-2-one, in which only the use of glycerol (or water) afforded the desired products 3-4 in good yields without the assistance of any Brønsted or Lewis acid catalyst (Scheme 8). ${ }^{40,41}$

Although reasons behind the promoting effect of glycerol in these addition reactions are not entirely clear, it is suspected that the strong hydrogen bond network of glycerol might be responsible, similarly to the well-known accelerating effect exerted by water in many organic reactions. However, at present it cannot be totally ruled out that the presence of trace amounts of impurities (acidic or basic derivatives) can act as a possible catalyst. ${ }^{14}$

Importantly, the Michael-type addition reactions depicted in Schemes 7 and 8 also proceeded efficiently in technical grade glycerol, ${ }^{40}$ which is much more appealing from the viewpoint of Green Chemistry since purification of crude glycerol from biodiesel production is a costly and energy consuming process. $^{6}$ In this context, we must note that crude glycerol, generated from various vegetable oil sources, was also

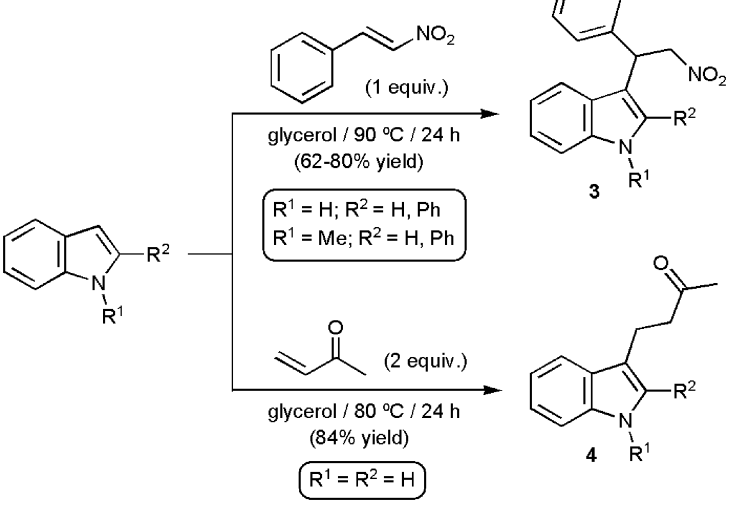

Scheme 8 Catalyst-free Friedel-Crafts alkylations of indoles in glycerol.

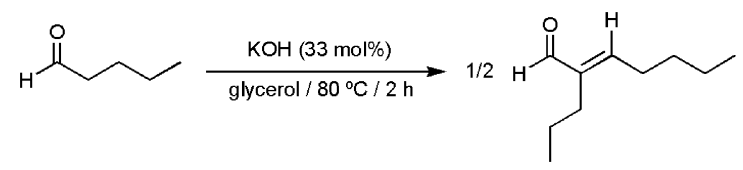

Scheme 9 Base-catalyzed aldol condensation of $n$-valeraldehyde.

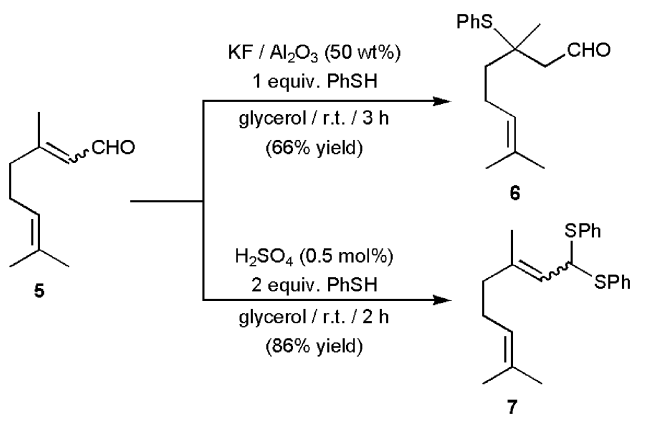

Scheme 10 Addition of thiophenol to citral in glycerol.

successfully employed by Wolfson's group as a green solvent in the $\mathrm{KOH}$-catalyzed aldol condensation of $n$-valeraldehyde (Scheme 9). However, for this particular reaction lower conversions compared to that reached in pure glycerol were observed $(31-43 \%$ vs. $52 \%){ }^{42}$

Michael addition of thiophenol to citral $\mathbf{5}$ was also studied in glycerol (Scheme 10). ${ }^{43}$ In the absence of any catalyst a mixture of two products, 6 and 7, resulting from the conjugated 1,4- or double 1,2-addition, respectively, of $\mathrm{PhSH}$ to the enal unit was obtained. However, the selectivity of the process could be finely tuned by using an appropriate acid or base catalyst. Thus, over basic $\mathrm{KF} / \mathrm{Al}_{2} \mathrm{O}_{3}$, the reaction was oriented towards the formation of the 1,4-adduct $\mathbf{6}$, whereas in the presence of $\mathrm{H}_{2} \mathrm{SO}_{4}$ the 1,2-addition product 7 was exclusively generated. In the presence of $\mathrm{KF} / \mathrm{Al}_{2} \mathrm{O}_{3}$, other aliphatic and aromatic thiols were selectively added to citral, and related electron-poor alkenes, in glycerol. Note that the catalyst and solvent could be effectively recycled after extraction of the reaction products with diethyl ether.

Glycerol was also an excellent promoting medium for the ring-opening of styrene oxide with $p$-anisidine (Scheme 11). ${ }^{40}$ In this case no catalysts were needed to reach a good selectivity. Indeed, it was remarkably higher to that observed when the reaction was performed in aqueous medium under identical conditions ( $\mathbf{8} / \mathbf{9}$ ratio $=93 / 7$ vs. $76 / 24)$. Good results were also observed in the acid-catalyzed dehydrative dimerization of

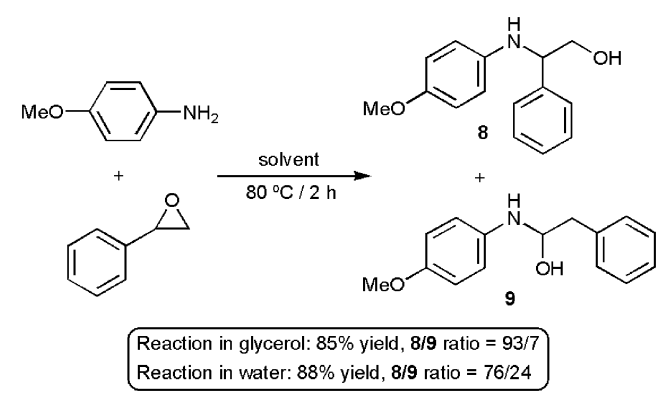

Scheme 11 Ring-opening of styrene oxide with $p$-anisidine. 


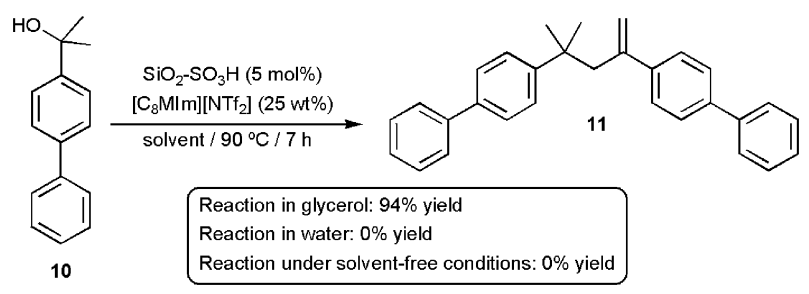

Scheme 12 Acid-catalyzed dehydrative dimerization of alcohol 10.

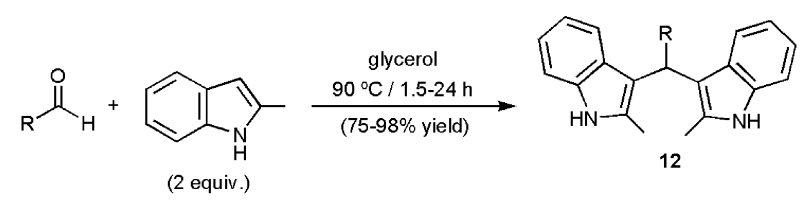

$\mathrm{R}=\mathrm{Ph}, 4-\mathrm{C}_{6} \mathrm{H}_{4} \mathrm{Me}, 2-\mathrm{C}_{6} \mathrm{H}_{4} \mathrm{NO}_{2}, 4-\mathrm{C}_{6} \mathrm{H}_{4} \mathrm{NO}_{2}, 4-\mathrm{C}_{6} \mathrm{H}_{4} \mathrm{OMe}, 2-\mathrm{C}_{6} \mathrm{H}_{4} \mathrm{OMe}, 4-\mathrm{C}_{6} \mathrm{H}_{4} \mathrm{NMe}_{2}$, 4- $\mathrm{C}_{6} \mathrm{H}_{4} \mathrm{OH}, 2-\mathrm{C}_{6} \mathrm{H}_{4} \mathrm{OH}, 4-\mathrm{C}_{6} \mathrm{H}_{4} \mathrm{Cl}, 4-\mathrm{C}_{6} \mathrm{H}_{4} \mathrm{OAc}, 4-\mathrm{C}_{6} \mathrm{H}_{4} \mathrm{NHAc}, 3,4-\mathrm{C}_{6} \mathrm{H}_{3}(\mathrm{OMe})_{2}$, 2-OH-3- $\mathrm{C}_{6} \mathrm{H}_{3} \mathrm{OEt}, 2-\mathrm{OH}-5-\mathrm{C}_{6} \mathrm{H}_{3} \mathrm{Br}$, 3-OMe-4- $\mathrm{C}_{6} \mathrm{H}_{3} \mathrm{OH}, 2$-furyl, $\mathrm{CH}_{2} \mathrm{CH}_{2} \mathrm{Ph}$

Scheme 13 Catalyst-free synthesis of bis(indolyl)methanes in glycerol.

alcohol 10, where only the use of glycerol led to the formation of the desired product 11 (Scheme 12). ${ }^{40}$

In the context of a broad study, Gu and co-workers have demonstrated that glycerol is an advantageous solvent for the electrophilic activation of aldehydes. ${ }^{44}$ Thus, as shown in Scheme 13, several bis(indolyl)methane derivatives 12 could be efficiently synthesized by a thermal reaction between 2-methylindole and aldehydes, without using any acid catalyst. Aromatic, heteroaromatic and aliphatic aldehydes, including the acid-sensitive furfural and 4-dimethylaminobenzaldehyde, were tolerated and the process could be satisfactorily extended to other indole derivatives (1-methylindole, 2-phenylindole, 2-methyl-5-methoxyindole, 1-methyl-2-phenylindole or indole itself). ${ }^{45}$ The only limitation was found in the reactions with ketones, which were completely inoperative in the process. For comparative purposes, the suitability of other solvents, such as toluene, DMF, DMSO, n-butyl acetate, n-butanol, ethylene glycol, polyethylene glycol (PEG-400) and water, in these catalyst-free coupling reactions was evaluated under the same experimental conditions. In all cases, the desired products were obtained either in a trace amount or in a significantly lower yield than in glycerol. Moreover, taking advantage of the insolubility of bis(indolyl)methanes $\mathbf{1 2}$ in glycerol, at the end of the reaction, they could be easily isolated by simple filtration.

Glycerol also promoted the condensation of aromatic, heteroaromatic and $\alpha, \beta$-unsaturated aldehydes with 1,3-cyclohexanedione to generate selectively the corresponding xanthene-1,8(2H)-diones 13, or the isomeric 1-oxo-hexahydroxanthenes $\mathbf{1 4}$ if salicylaldehydes are used as starting materials, reactions that are conventionally carried out using acid catalysts (Scheme 14). ${ }^{44}$

Thioacetals are useful carbonyl protecting groups in organic synthesis due to their inherent stability towards ordinary acidic and basic conditions. ${ }^{46}$ As in the precedent transformations, thioacetalization reactions usually require the assistance of protic or Lewis acids. However, taking advantage of the activating effect of glycerol towards $\mathrm{C}=\mathrm{O}$ bonds, an appealing
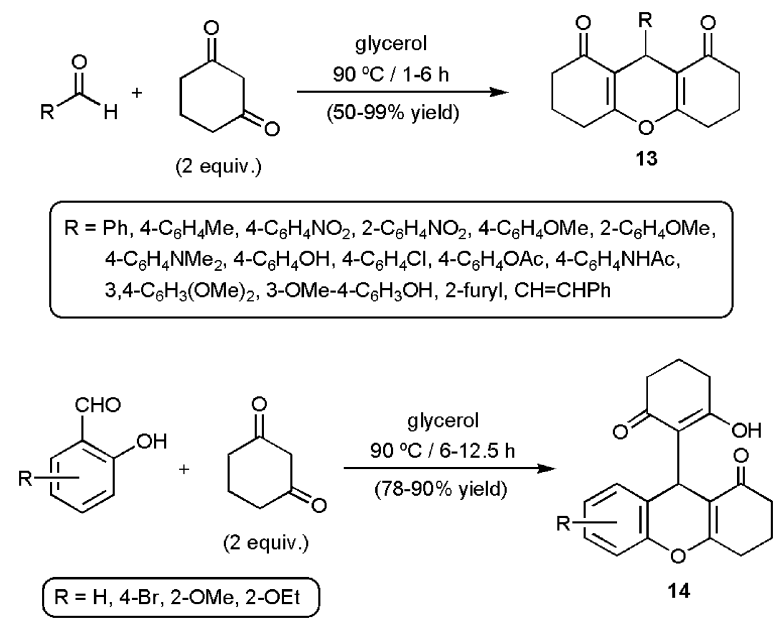

Scheme 14 Catalyst-free condensations of aldehydes with 1,3-cyclohexanedione in glycerol.

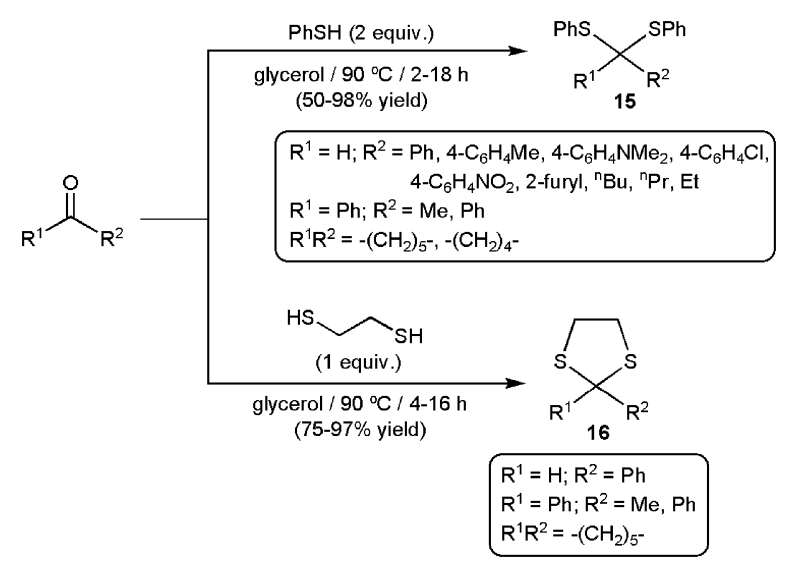

Scheme 15 Thioacetalization of carbonyl compounds in glycerol.

and general catalyst-free thioacetalization protocol has been recently described using glycerol as solvent. ${ }^{47}$ Thus, as shown in Scheme 15, several aldehydes and ketones could be successfully thioacetylated with benzenethiol or 1,2-ethanedithiol just by heating in glycerol at $90{ }^{\circ} \mathrm{C}$. The resulting thioacetals 15-16 were isolated in good yields after extraction of the crude reaction mixtures with hexanes, and subsequent chromatographic purification. In addition, glycerol could be reused for further thioacetalizations maintaining its good level of efficiency after four consecutive runs.

Multicomponent reactions (MCRs), in which three or more reactants are combined in a single chemical step, comply with most of the requirements for an ideal organic synthesis (structural complexity from readily available starting materials, atom economy, operational simplicity, resource effectivity, etc.). ${ }^{48}$ In this context, glycerol also proved to be a convenient platform to perform this type of transformations. In particular, many substrates, such as styrenes, primary amines, 2-naphthol, 4-hydroxy-6-methyl-2-pyrone and 4-hydroxy-1methyl-2-quinolone, could be readily assembled with 1,3-cyclohexadiones and formaldehyde in glycerol, under catalyst-free conditions, to afford the elaborated polycyclic compounds 17-21 in moderate to high yields (Scheme 16). ${ }^{49} \mathrm{In}$ 

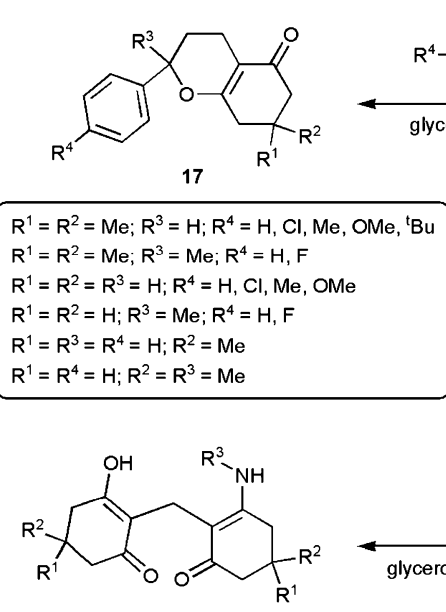

18

$\mathrm{R}^{1}=\mathrm{R}^{2}=\mathrm{Me} ; \mathrm{R}^{3}=\mathrm{Ph}, 4-\mathrm{C}_{6} \mathrm{H}_{4} \mathrm{Me}, 4-\mathrm{C}_{6} \mathrm{H}_{4} \mathrm{OMe}, \mathrm{Bn}, \mathrm{C}$ $\mathrm{R}^{1}=\mathrm{R}^{2}=\mathrm{H} ; \mathrm{R}^{3}=\mathrm{Cy}$

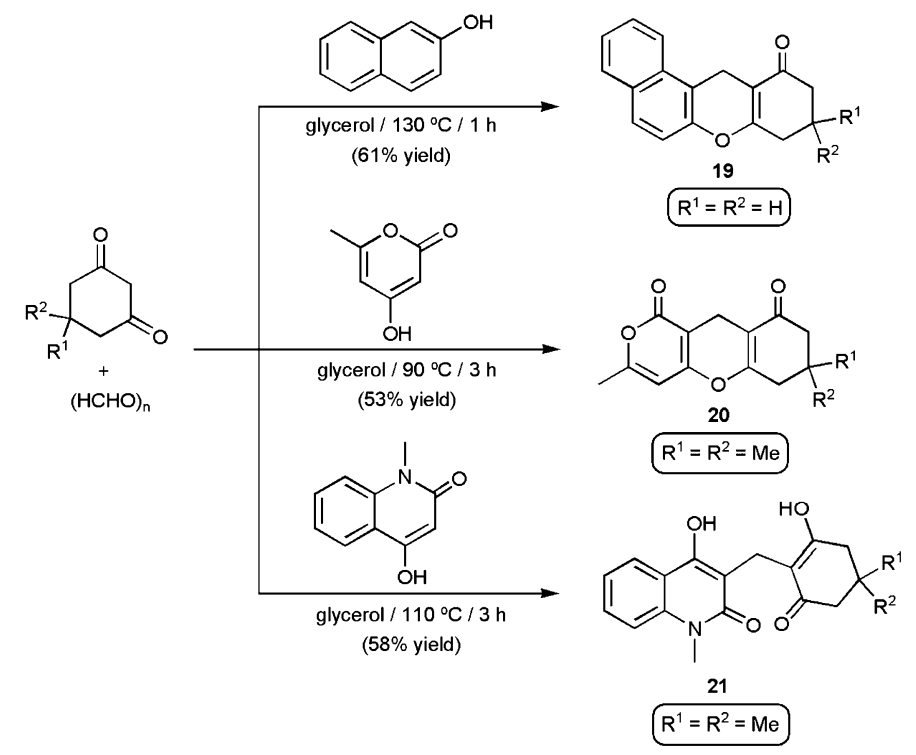

Scheme 16 Multicomponent reactions of 1,3-cyclohexanediones and formaldehyde in glycerol. these MCRs, glycerol not only showed a significant beneficial effect on the reaction yields compared to more classical organic solvents (toluene, nitromethane, DMF or DMSO) and water, but also allowed easy separation of the products 17-21 by means of extraction with ethyl acetate.

The reaction of styrene with dimedone and paraformaldehyde was studied in great detail and the positive effect of glycerol could be attributed to two factors: (i) a restricted formation of the oxo-diene intermediate 22 (Scheme 17), resulting from the initial Knoevenagel condensation between dimedone and formaldehyde, and (ii) the enhancing effect of glycerol on the rate of the subsequent hetero-Diels-Alder reaction of $\mathbf{2 2}$ with styrene due to its polar character. In this sense, during the reaction, the authors observed the formation of a thin shell, mainly composed of the insoluble by-product $\mathbf{2 3}$ generated at the beginning of the reaction, on the surface of solid paraformaldehyde (NMR analysis). ${ }^{49}$ This coating of paraformaldehyde by $\mathbf{2 3}$ in glycerol, not observed when water and other organic compounds were used as solvents, inhibits its decomposition and controls the formation of the key intermediate 22. Thus, 22 is formed gradually and it is immediately consumed in the Diels-Alder step without time to evolve into $\mathbf{2 3}$, the major reaction product observed using other solvents.
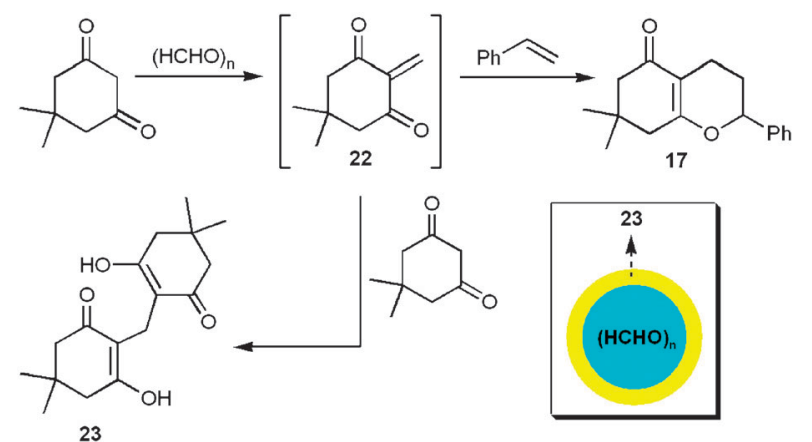

Scheme 17 Reaction pathway involved in the formation of $\mathbf{1 7}$.

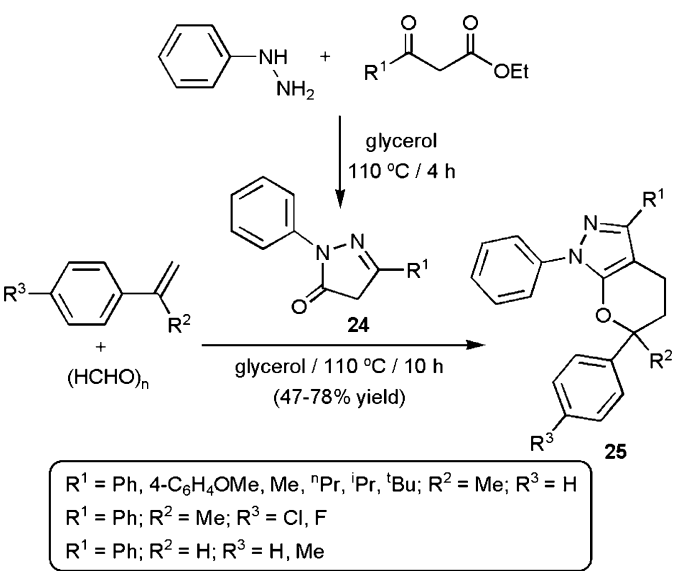

Scheme 18 Four-component two-step sequential reactions in glycerol.

The utility of glycerol in MCRs was further demonstrated in the preparation of the polyheterocycles $\mathbf{2 5}$ through a one-pot two-step sequential coupling of phenylhydrazine, $\beta$-keto esters, formaldehyde and styrenes (Scheme 18). ${ }^{50}$ In the first step a 1,3-disubstituted 5-pyrazolone $\mathbf{2 4}$ is selectively formed by condensation between phenylhydrazine and the $\beta$-keto ester. Subsequent addition of the styrene derivative and paraformaldehyde to the reaction mixture generates 25 through a tandem Knoevenagel/hetero-Diels-Alder reaction.

A related sequential transformation involving the coupling of phenylhydrazine, a $\beta$-keto ester, formaldehyde and 1-ethyl2-phenylindole in glycerol has also been described, the process allowing the preparation of the highly functionalized indole derivative $\mathbf{2 6}$ in $42 \%$ yield (Scheme 19). ${ }^{50}$

Using the aminopolysaccharide $\mathbf{2 7}$ as a surfactant-combined basic catalyst, chemoselective ring-opening of epoxides with carboxylic acids to afford the corresponding esters $\mathbf{2 8}$ could be achieved in glycerol (Scheme 20). ${ }^{51}$ Remarkably, the use of conventional basic catalysts, such as $\mathrm{ZnO}, \mathrm{K}_{2} \mathrm{CO}_{3}$ or secondary amines, resulted in lower reaction rates and selectivities since 


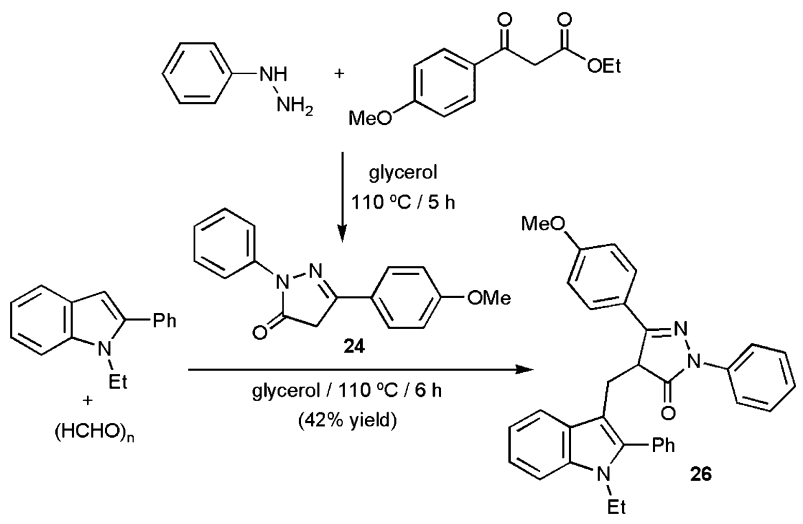

Scheme 19 Synthesis of the functionalized indole $\mathbf{2 6}$.

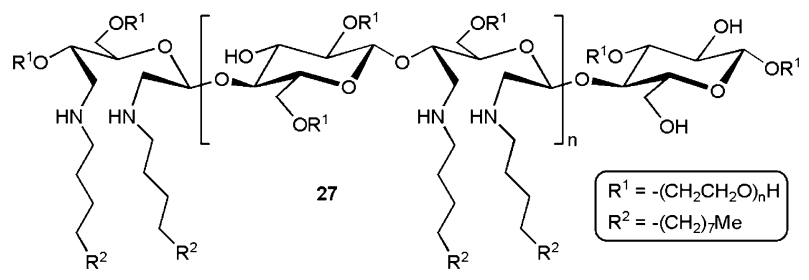

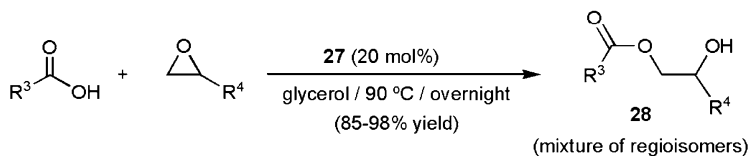$$
\begin{aligned}
& \mathrm{R}^{3}=-\left(\mathrm{CH}_{2}\right)_{7} \mathrm{CH}=\mathrm{CH}_{2},-\left(\mathrm{CH}_{2}\right)_{17} \mathrm{OH}, \mathrm{CH}_{2}-3,4-\mathrm{C}_{6} \mathrm{H}_{3}(\mathrm{OMe})_{2}, \mathrm{Cy} ; \mathrm{R}^{4}=-\left(\mathrm{CH}_{2}\right)_{9} \mathrm{Me} \\
& \mathrm{R}^{3}=-\left(\mathrm{CH}_{2}\right)_{7} \mathrm{CH}=\mathrm{CH}\left(\mathrm{CH}_{2}\right)_{7} \mathrm{Me},-\left(-\left(\mathrm{CH}_{2}\right)_{10} \mathrm{CHOH}\left(\mathrm{CH}_{2}\right)_{5} \mathrm{Me} ; \mathrm{R}^{4}=--\left(\mathrm{CH}_{2}\right)_{9} \mathrm{Me}\right. \\
& \mathrm{R}^{3}=-\left(-\mathrm{CH}_{2}\right)_{10} \mathrm{CHOH}\left(\mathrm{CH}_{2}\right)_{5} \mathrm{Me} ; \mathrm{R}^{4}=-\left(\mathrm{CH}_{2}\right)_{6} \mathrm{CH}=\mathrm{CH}_{2} \\
& R^{3}=-\left(-\left(\mathrm{CH}_{2}\right)_{10} \mathrm{Me} ; \mathrm{R}^{4}=-\left(\mathrm{CH}_{2}\right)_{6} \mathrm{CH}=\mathrm{CH}_{2}, \mathrm{CH}_{2} \mathrm{OBn}\right.
\end{aligned}
$$

Scheme 20 Catalytic ring-opening of epoxides with carboxylic acids.

formation of ethers, derived from the ring-opening of the epoxides with glycerol, as by-products was observed. Apparently, the aminopolysaccharide $\mathbf{2 7}$ favours a better diffusion of the organic reactants in glycerol, limiting also the reactivity of this polyol. In addition, the emulsions formed in glycerol were found to be unstable. Thus, after centrifugation, the reaction media rapidly became biphasic, which allowed easy separation of the reaction products without assistance of any organic solvent. This particular property of glycerol also enabled the homogeneous catalyst $\mathbf{2 7}$ to be recycled up to ten times without any change in activity or selectivity. The versatility of the aminopolysaccharide $\mathbf{2 7}$ as catalyst was further demonstrated by conducting successfully other classical base-catalyzed reactions in glycerol, such as the Knoevenagel condensation of benzaldehyde with malononitrile, the Henry condensation of benzaldehyde with nitroethane or the Michael addition of nitroethane to 2-cyclohexen-1-one. ${ }^{51}$

Selective ring-opening reactions of epoxides with carboxylic acids were also performed in glycerol using poly(propylene)imine (PPI) dendrimers, decorated on the surface with glyceryl moieties, as basic catalysts (as a representative example the 2 nd generation of these functionalized PPI dendrimers $\mathbf{2 9}$ is given in Fig. 3). ${ }^{52}$ Owing to the presence of glyceryl units surrounding the PPI core, the dendritic catalysts were successfully immobilized in glycerol, which also facilitated the separation of the products $\mathbf{2 8}$ and a convenient dendrimer-recycling.

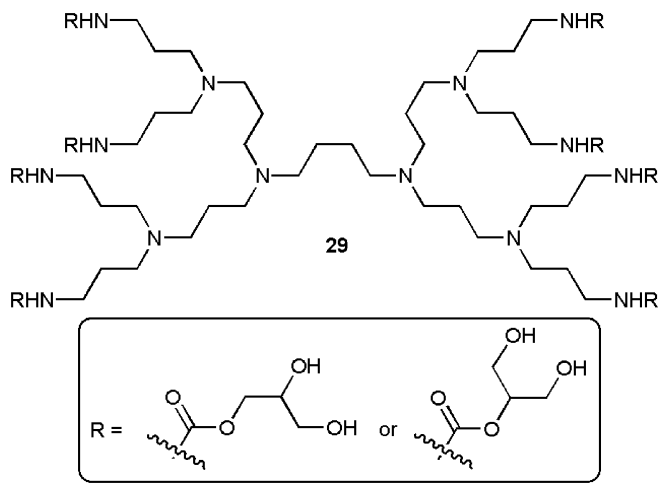

Fig. 3 PPI dendrimer used in the catalytic ring-opening of epoxides.

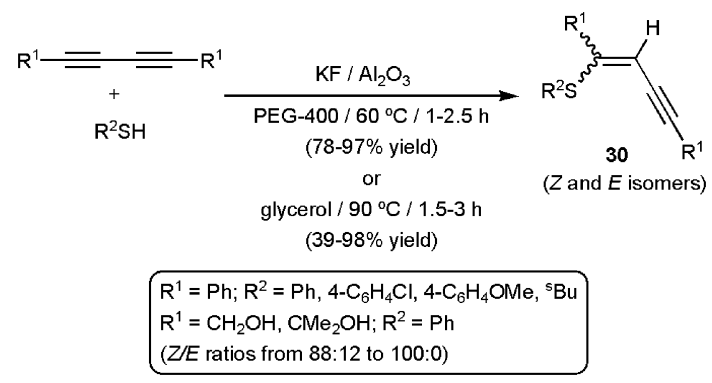

Scheme 21 Hydrothiolation of 1,3-butadiynes in PEG-400 and glycerol.

A green and general protocol for the synthesis of thiobutenynes 30 in glycerol, through the heterogeneous $\mathrm{KF} / \mathrm{Al}_{2} \mathrm{O}_{3}$-catalyzed hydrothiolation of disubstituted 1,3butadiynes, was developed by Perin and co-workers (Scheme 21) ${ }^{53}$ However, we must note that, for this particular transformation, the use of polyethylene glycol (PEG-400) resulted more advantageous since higher yields at lower temperatures $\left(60 \mathrm{vs} .90{ }^{\circ} \mathrm{C}\right)$ were in general reached. Formation of $Z$-isomers was preferential in both media and the solvent/ catalyst systems could be reused up to three times with comparable activities and $Z$-selectivities.

PEG-400 and glycerol were similarly employed as recyclable solvents for hydrochalcogenation reactions of phenylacetylene (Scheme 22). ${ }^{54}$ The nucleophilic species of selenium and tellurium were in this case generated in situ from the corresponding diphenyl dichalcogenide and $\mathrm{NaBH}_{4}$ at $60{ }^{\circ} \mathrm{C}$. Interestingly, while the reactions conducted in PEG-400 afforded selectively the corresponding $(Z)-\beta$-phenylchalcostyrenes 31, the formation of a mixture of the $E$ and $Z$ isomers of the dichalcogenated

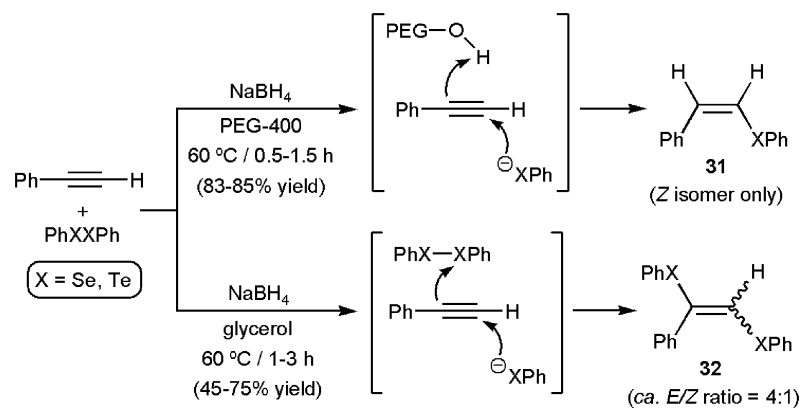

Scheme 22 Hydrochalcogenation reactions of phenylacetylene. 


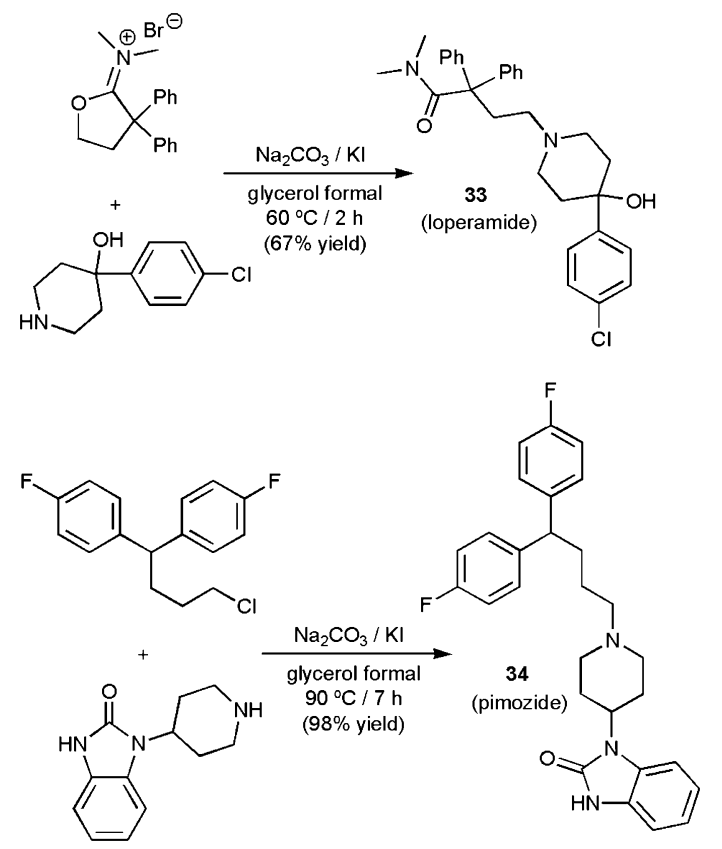

Scheme 23 Synthesis of loperamide and pimozide in glycerol formal.

alkenes 32 was observed when glycerol was used as solvent. The lower solubility of the starting materials in glycerol vs. PEG-400 was evoked to explain the different reactivities observed.

Recent years have also seen the use of different glycerol derivatives as green solvents in synthetic organic chemistry. In this context, improved processes for the preparation of the antidiarrhetic and antipsychotic drugs loperamide 33 and pimozide 34, respectively, have been patented using glycerol formal (Scheme 23). ${ }^{55}$ This inert solvent conveniently replaces the methyl isobutyl ketone employed in the most classical preparations. In addition, glycerol formal exhibits a superior technical performance than methyl isobutyl ketone as evidenced by the lower equivalents of base required (1.1 vs. 1.6-2.6 equiv. of $\mathrm{Na}_{2} \mathrm{CO}_{3}$ ), the reduced temperature regime $\left(60-90\right.$ vs. $\left.120^{\circ} \mathrm{C}\right)$, the shorter reaction times $(2-7$ vs. $15-65 \mathrm{~h})$, and the possibility of carrying out an aqueous work-up, thus simplifying the isolation and purification of the products.

Within a broad comparative study, a family of 13 common solvents and 18 glycerol-based ethers (1,3-dialkoxy-2-propanols and 1,2,3-trialkoxypropanes) were evaluated as suitable reaction media for cyclooctene epoxidation with $\mathrm{H}_{2} \mathrm{O}_{2}$ using bis[3,5bis(trifluoromethyl)phenyl]diselenide $\mathbf{3 5}(1 \mathrm{~mol} \%)$ as a catalyst (Scheme 24). ${ }^{56}$ Although the best results were achieved in 2,2,2-trifluoroethanol (TOF $=491 \mathrm{~h}^{-1}$ ), the use of some glycerol-based ethers bearing fluorinated alkyl chains also allowed fast conversions (TOF $=130-214 \mathrm{~h}^{-1}$ ). Indeed, some of them performed better than dichloromethane $\left(\mathrm{TOF}=153 \mathrm{~h}^{-1}\right)$, which is one of the most commonly used solvents in these epoxidation reactions. As in the case of 2,2,2trifluoroethanol, the activating properties towards $\mathrm{H}_{2} \mathrm{O}_{2}$ via hydrogen bonding have been evoked to explain the beneficial effect of these new reaction media. The range of applicability of this catalytic transformation was successfully extended to the epoxidation of the more challenging olefin cyclohexene. ${ }^{57}$

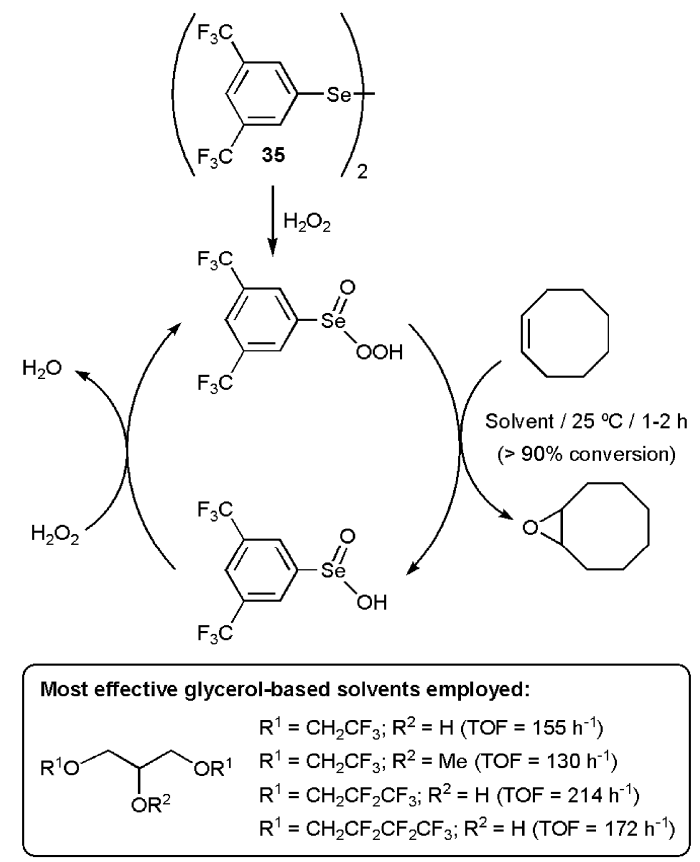

Scheme 24 Epoxidation of cyclooctene in glycerol-derived solvents.

It is also important to note that recycling of the catalytically active phase, i.e. fluorinated solvent + selenium catalyst, was possible through distillation of the cyclohexene oxide from the reaction mixture.

Ionic liquids (ILs) are widely used in carbohydrate chemistry owing to their unique ability to dissolve a large number of mono-, oligo- and polysaccharides. ${ }^{58}$ In this context, their use as solvents for the acid-catalyzed dehydration of fructose $\mathbf{3 6}$ to 5-hydroxymethylfurfural $\mathbf{3 7}$ (HMF), a useful synthetic intermediate in the preparation of a wide range of fine chemicals, has been extensively investigated in recent years. ${ }^{59}$ However, the high prices and toxicity of ILs are major obstacles to the practical application of these methodologies at the productive scale. As a possible solution, Jérôme and co-workers have demonstrated that ILs can be partially substituted by inexpensive and safe glycerol carbonate. ${ }^{60}$ Thus, as shown in Table 2, using the acidic ion-exchange resin Amberlyst 70 as a catalyst, up to $80 \mathrm{wt} \%$ of 1-butyl-3-methyl imidazolium chloride ([BMIM]Cl) could be replaced by glycerol carbonate without a dramatic effect on the HMF yield (entries 1-4). The glycerol carbonate content could be further increased from 80 to $90 \mathrm{wt} \%$ working under biphasic (entry $6 v s .5$ ) or more diluted conditions (entry $7 v s .5$ ), the use of a biphasic media ([BMIM]Cl/glycerol acetate-methyl isobutyl ketone) allowing also the effective separation of $\mathbf{3 7}$ since it selectively dissolves in the methyl isobutyl ketone phase. Similar studies were also performed with pure and crude glycerol instead of glycerol carbonate ${ }^{60}$ However, in these cases only $35 \mathrm{wt} \%$ of [BMIM]Cl could be effectively replaced since side reactions between glycerol and $\mathbf{3 7}$ occur at higher glycerol contents.

Using Amberlyst 70 as catalyst, direct production of $\mathrm{HMF}$ 37 in a [BMIM]Cl/glycerol carbonate mixture (10:90 wt \%) could be achieved starting from inulin 38, a natural polysaccharide extracted from chicory or dahlia tubers (Scheme 25). ${ }^{60}$ 
Table 2 Acid-catalyzed dehydration of fructose in [BMIM]Cl/glycerol carbonate mixtures $^{a}$

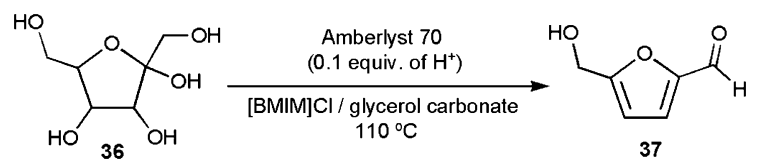

\begin{tabular}{llll} 
Entry & {$[\mathrm{BMIM}] \mathrm{Cl} /$ glycerol carbonate $(\mathrm{wt} \%$ ratio) } & $t / \mathrm{min}$ & Yield $(\%)$ \\
\hline 1 & $100: 0$ & 15 & 95 \\
2 & $65: 35$ & 35 & 98 \\
3 & $50: 50$ & 30 & 91 \\
4 & $20: 80$ & 25 & 75 \\
5 & $10: 90$ & 20 & 60 \\
$6^{b}$ & $10: 90$ & 30 & 70 \\
$7^{c}$ & $10: 90$ & 40 & 72 \\
8 & $0: 100$ & 20 & 10
\end{tabular}

${ }^{a}$ Reactions performed at $110{ }^{\circ} \mathrm{C}$ using $1 \mathrm{~g}$ of fructose, $2.5 \mathrm{~g}$ of the [BMIM] Cl/glycerol carbonate mixture and Amberlyst 70 (0.1 equiv. $\left.\mathrm{H}^{+}\right) .{ }^{b}$ Reaction performed in the presence of methyl isobutyl ketone. ${ }^{c}$ Reaction performed starting from $0.5 \mathrm{~g}$ of fructose dissolved in $2.5 \mathrm{~g}$ of the $[\mathrm{BMIM}] \mathrm{Cl} / \mathrm{glycerol}$ carbonate mixture.

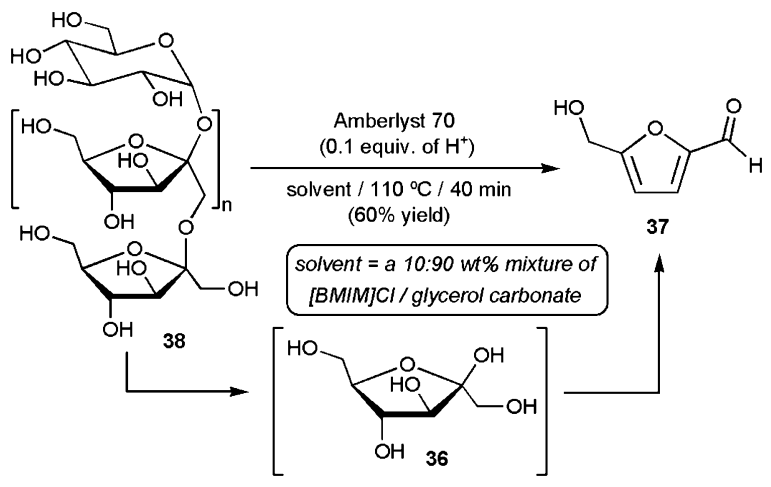

Scheme 25 Acid-catalyzed production of HMF from inulin.

As proposed by the authors, the residual water contained in the acidic resin (54-59 $\mathrm{wt} \%)$ is able to promote the initial hydrolysis of 38 to fructose 36, which subsequently undergoes the acidcatalyzed dehydration reaction.

Finally, an efficient and green synthesis of isoamyl acetate 40, an industrially relevant food additive because of its characteristic banana flavor, has been described by transesterification of isoamyl alcohol 39 employing Amberlyst 36 as a catalyst, and triacetin (glycerol triacetate) as both an acyl donor and a solvent (Scheme 26). ${ }^{61}$ The use of triacetin enabled easy isolation of the product by simple extraction with petroleum ether, as well as separation and recycling of the heterogeneous catalyst by filtration. Experiments conducted in a domestic microwave oven also revealed the compatibility of

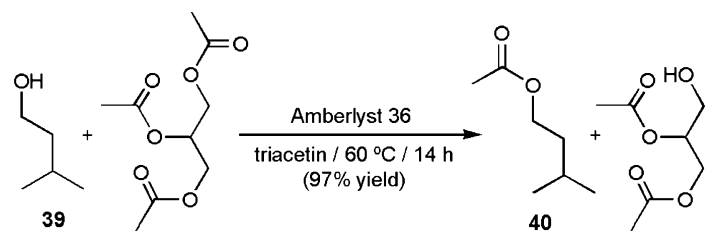

Scheme 26 Transesterification of isoamyl alcohol in triacetin. this transesterification process with MW heating (a 100-fold increase in the reaction rate was observed).

\section{Transition-metal catalyzed reactions}

Early attempts to use glycerol as solvent for metal-catalyzed reactions were reported in 1968 by Tarama and Funabiki, who studied the partial reduction of butadiene into butene in a glycerol/methanol solvent mixture $(1: 1 \mathrm{v} / \mathrm{v}){ }^{62}$ Unfortunately, the hydrogenation process, performed at $20{ }^{\circ} \mathrm{C}$ and promoted by pentacyanocobaltate(II) generated in situ from $\mathrm{CoCl}_{2}$ and an excess of $\mathrm{KCN}$, proceeded with lower rates and selectivities than in $\mathrm{H}_{2} \mathrm{O}$. Thus, while 1-butene was almost the only isomer generated in water, an approximately 50/40/10 ratio of 1-butene/cis-2-butene/trans-2-butene was obtained in glycerol/MeOH.

Despite this early interest, glycerol has only been recognized as a useful solvent for catalysis in very recent years. In this sense, works by Wolfson and co-workers in 2007 demonstrated that glycerol is a suitable medium for Heck-type $\mathrm{C}-\mathrm{C}$ couplings. ${ }^{38,63}$ In particular, using the cross-coupling between iodobenzene and $n$-butyl acrylate as model reaction, they evaluated the catalytic activities of several palladium species in pure glycerol (Scheme 27). Best results were obtained using $\mathrm{PdCl}_{2}, \mathrm{Pd}(\mathrm{OAc})_{2}$ and $\left[\mathrm{Pd}(\mathrm{OAc})_{2}(\mathrm{TPPTS})_{2}\right]$ (TPPTS = tris(3-sulfophenyl)phosphine trisodium salt), associated with $\mathrm{Na}_{2} \mathrm{CO}_{3}$, which led to the selective formation of $n$-butyl cinnamate $41 \mathrm{a}$ in $32-100 \%$ yield after $4 \mathrm{~h}$ at $80{ }^{\circ} \mathrm{C}$. Worthy of note, this chemical transformation could be considerably accelerated under microwave irradiation. Thus, using a domestic MW oven with a temperature rise from 26 to $117{ }^{\circ} \mathrm{C},\left[\mathrm{Pd}(\mathrm{OAc})_{2}(\mathrm{TPPTS})_{2}\right]$ as a catalyst and $\mathrm{Na}_{2} \mathrm{CO}_{3}$ as a base, 41a could be generated in $93 \%$ yield after only $10 \mathrm{~min}$ of irradiation.

The Heck coupling of iodobenzene was also operative with $i$-butyl acrylate and styrene, furnishing $i$-butyl cinnamate $\mathbf{4 1 b}$ and stilbene 41c, respectively, in high yields. Alternatively, bromobenzene could also be employed as starting material, although in this case, as usually observed in Heck reactions, the efficiency of the process was significantly reduced. ${ }^{63}$ Interestingly, these catalytic reactions were compatible with the use of crude glycerol as solvent, albeit slightly lower conversions than in pure glycerol were in general reached. ${ }^{42}$ This decrease in activity has been attributed to the presence of fatty acid salts in the solvent, impurities presumably able to deactivate the catalytically active species. However, it is important to note that, when crude glycerol was used as solvent, addition of a base was not required since basic residues present in the solvent are sufficient to generate the catalytically active $\operatorname{Pd}(0)$ species.

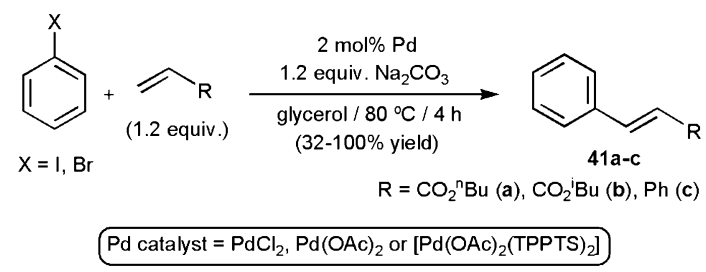

Scheme 27 Heck-type reactions performed in glycerol. 
Related cross-coupling reactions between ethyl acrylate and iodobenzene have also been investigated by Bellina and co-workers employing the glycerol-based ionic liquids $\mathbf{C}$ as solvents (Fig. 2) ${ }^{30}$ Reactions performed at $100{ }^{\circ} \mathrm{C}$ in the presence of $5 \mathrm{~mol} \%$ of $\mathrm{PdCl}_{2}$ and $\mathrm{NaOAc}$ (1.1 equiv.) delivered the desired ethyl cinnamate in variable yields after $1 \mathrm{~h}(3-87 \%)$. In general, better results were obtained on increasing the length of the alkyl chain in the cation, that is, on increasing the lipophilicity of the solvent. Unfortunately, reuse of these IL systems was not very encouraging due to the considerable loss of activity after the first recycling.

In contrast to classical monoarylation processes, which have found widespread applications in organic synthesis, efficient $\beta, \beta$-diarylations of alkenes remain scarce. ${ }^{64}$ Such a double $\mathrm{C}-\mathrm{C}$ couplings are generally favoured at high temperatures, hence glycerol can be particularly adequate for such transformations. Accordingly, Jérôme and co-workers have recently reported the high yield synthesis of a variety of diaryl alkenes $\mathbf{4 3}$ through the diarylation of acrylates with iodoarenes in this medium (Scheme 28) ${ }^{65}$ Reactions promoted by palladium nanoparticles stabilized over the aminopolysaccharide 27 (see Scheme 20) and triethylamine were carried out in the presence of 3 equivalents of the corresponding aryl iodides at $120{ }^{\circ} \mathrm{C}$ for $30 \mathrm{~h}$. Interestingly, under these experimental conditions no monoarylated derivatives were detected in the crude reaction mixtures, although small amounts $(<10 \%)$ of biphenyls, typical homo-coupling side-products in Heck-type reactions, were produced. It is also noteworthy that diaryl alkenes $\mathbf{4 3}$ showed a good stability in glycerol, which contrasts favorably with their behavior in aqueous media, where the ester moieties are prone to undergo partial hydrolysis making difficult their isolation in good yields. ${ }^{66}$

The catalytic system $\mathbf{P d} / \mathbf{2 7}$ is also suitable for performing the selective monoarylation of acrylates, just by decreasing the quantity of aryl iodide ( 1 vs. 3 equiv.) and the temperature ( 90 vs. $120^{\circ} \mathrm{C}$ ) employed. Taking advantage of this behavior, a convenient synthetic route to unsymmetrical diarylated alkenes $\mathbf{4 4}$ could be developed through the sequential Heck couplings of acrylates, first with iodobenzene at $90{ }^{\circ} \mathrm{C}$, and then with 2-iodonaphthalene at $120{ }^{\circ} \mathrm{C}$ (Scheme 29). ${ }^{65}$ Concerning the isolation of the products, the best results were achieved by extracting $\mathbf{4 3 - 4 4}$ from the glycerolic medium with $\mathrm{scCO}_{2}$, since the use of classical organic solvents led to concomitant extraction of the Pd/AP catalyst.

The feasibility of Suzuki-type processes in glycerol has also been demonstrated using the coupling between iodobenzene and phenyl boronic acid as model reaction (Scheme 30). ${ }^{63}$ The behavior of different palladium catalysts was evaluated in this transformation, finding that $\mathrm{Pd}(\mathrm{OAc})_{2}$ and $\left[\mathrm{Pd}(\mathrm{OAc})_{2}(\mathrm{TPPTS})_{2}\right]$ presented the highest activities, whereas the best recyclability

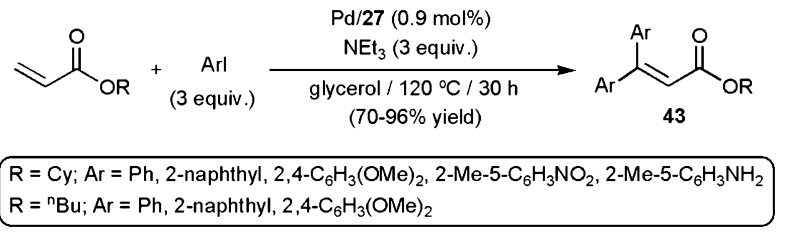

Scheme $28 \beta, \beta$-diarylation of acrylate derivatives in glycerol.

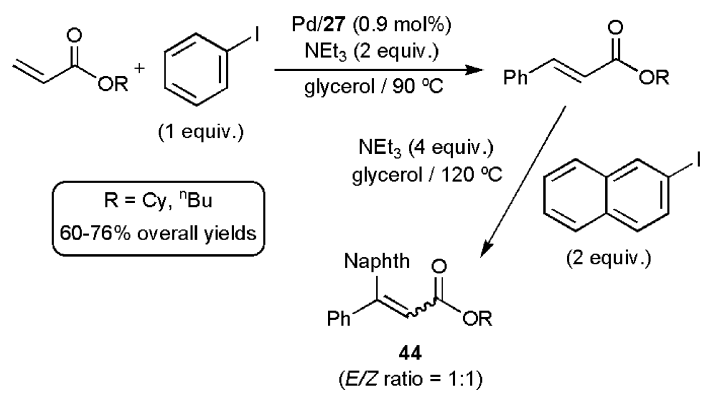

Scheme 29 Unsymmetrical $\beta, \beta$-diarylations of acrylates in glycerol.

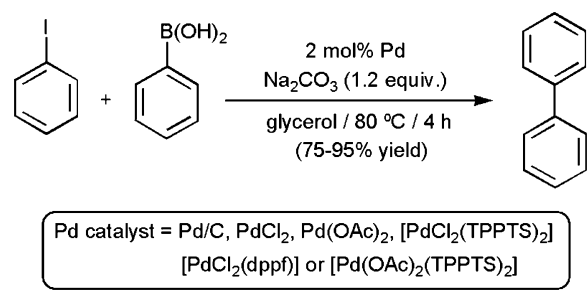

Scheme 30 Biphenyl synthesis through Suzuki coupling in glycerol.

(up to three consecutive runs without loss of activity) was provided by $\left[\mathrm{PdCl}_{2}(\mathrm{dppf})\right] \quad\left(\mathrm{dppf}=1,1^{\prime}\right.$-bis(diphenylphosphino)ferrocene).

Olefin metathesis is one of the most powerful tools presently available to generate new $\mathrm{C}-\mathrm{C}$ bonds, ${ }^{67}$ with recent efforts in this area being focused on the development of environmentally friendly procedures to perform this type of transformations. In this context, a wide variety of elaborated water-soluble metal-catalysts have been designed to realize these processes in aqueous media. ${ }^{68}$ The higher capacity offered by glycerol to dissolve transition-metal complexes has been recently exploited by Colacino and co-workers to develop ring closing metathesis $(\mathrm{RCM})$ reactions in this green medium using classical ruthenium-carbenes. ${ }^{69}$ In particular, they explored the efficiency of the first and second generations of Grubbs (45a-b), Hoveyda-Grubbs (46a-b) and Zhan (47a-b) catalysts in the RCM of $N, N$-diallyltosylamine 48 (Scheme 31). By performing the reactions at $40{ }^{\circ} \mathrm{C}$ under $\mathrm{MW}$-irradiation with a ruthenium loading of $5 \mathrm{~mol} \%$, all the catalysts checked proved to be active, with the most soluble one $47 \mathbf{b}$ showing the best performance (complete conversion after
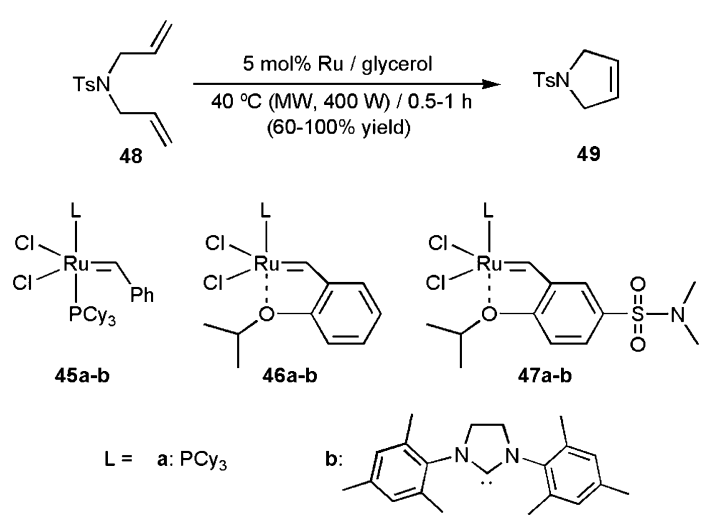

Scheme 31 Catalytic RCM of $N, N$-diallyltosylamine in glycerol. 


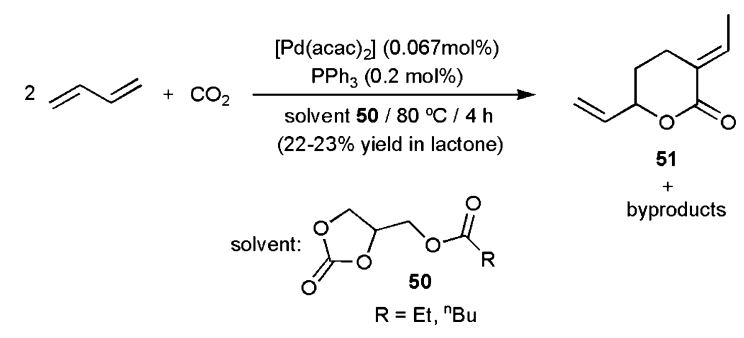

Scheme 32 Pd-catalyzed telomerization of butadiene with $\mathrm{CO}_{2}$.

$30 \mathrm{~min}$ of irradiation). The low solubility of $\mathrm{N}$-tosyl-2,5dihydro-1 $H$-pyrrole 49 in glycerol allowed its isolation by simple extraction with diethyl ether. In addition, after lyophilization to remove traces of water and $\mathrm{Et}_{2} \mathrm{O}$, the glycerolic phase containing the $\mathrm{Ru}$ catalyst could be reused in two further catalytic cycles without a significant loss of activity.

The potential of glycerol carbonate esters $\mathbf{5 0}$ to act as solvents for catalytic $\mathrm{C}-\mathrm{C}$ bond forming reactions was evaluated in the $\mathrm{Pd}$-catalyzed telomerization of butadiene with carbon dioxide to form the $\delta$-lactone 51 (Scheme 32). ${ }^{26}$ Control on the selectivity of this reaction towards 51, a valuable intermediate in organic synthesis, ${ }^{70}$ is a challenging task since several side reactions can occur, i.e. dimerization and oligomerization of butadiene, formation of acyclic acids and esters, etc. In this sense, although somewhat worse yields and selectivities were observed using carbonate esters $\mathbf{5 0}$ when compared with results obtained in lighter carbonates (ethylene-, propylene- and butylene-carbonate), only the use of these high-boiling point solvents allowed total separation of the product by distillation in a semi-technical scale, and the reuse of the catalytic system.

In addition to the early attempts made by Tarama and Funabiki to perform hydrogenations in a glycerolic medium, ${ }^{62}$ Wolfson and co-workers also investigated the hydrogenation of styrene into ethylbenzene in neat glycerol using [RhCl(TPPTS $)_{3}$ ] or $\mathrm{Pd} / \mathrm{C}$ as the catalyst (10 bar of $\mathrm{H}_{2}$, $\left.80{ }^{\circ} \mathrm{C}\right) .{ }^{38}$ Addition of Pluronic, a non-ionic surfactant, was necessary to compensate for the poor solubility of styrene in the medium, but even so the catalytic activities remained moderate. The same authors equally explored the hydrogenation of carbonyl compounds in glycerol $\left(10\right.$ bar of $\left.\mathrm{H}_{2}, 60{ }^{\circ} \mathrm{C}\right) .{ }^{39}$ Moderate yields on the reduced alcohols were reached with $\mathrm{Pd} / \mathrm{C}$ (52-60\%), while molecular rhodium or ruthenium precursors appeared to be almost inactive. The poor catalytic performances, inferior than those observed in methanol or toluene, were ascribed to the low solubility of hydrogen gas in glycerol. Note that, the use of the chiral ruthenium catalyst $\left[\mathrm{RuCl}\left(\eta^{6}-p\right.\right.$-cymene $)\{(S)$-BINAP $\left.\}\right][\mathrm{Cl}] \quad\left(\mathrm{BINAP}=2,2^{\prime}-\right.$ bis(diphenylphosphino)-1,1'-binaphthyl) in the hydrogenation of ethyl acetoacetate induced a high enantioselectivity $(99 \%$ ee, with $(S)$-ethyl-3-hydroxybutyrate as the major enantiomer), albeit with a very disappointing yield $(7 \%) .{ }^{39}$ Despite its limited potential, this reaction merits to be highlighted since it stands as the first example of an asymmetric metal-catalyzed process carried out in glycerolic media. ${ }^{71}$

More recently, high enantioselectivities, combined with excellent yields, have been described for the Co(II)-catalyzed

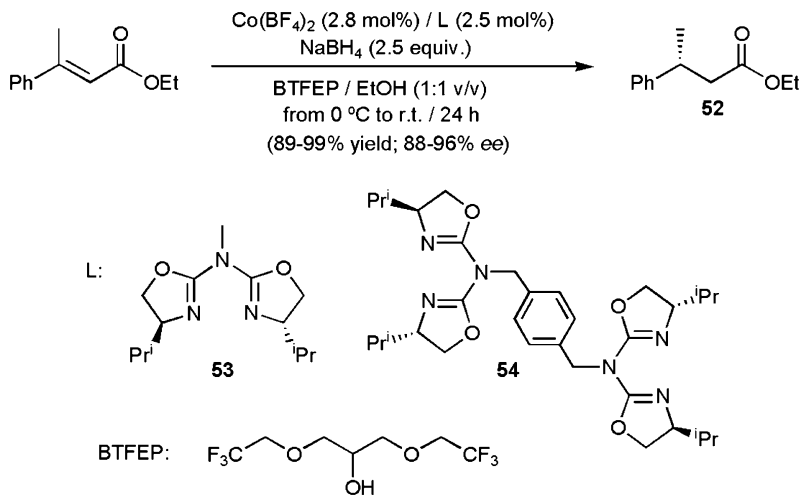

Scheme $33 \mathrm{Co}(\mathrm{II})$-catalyzed enantioselective $\mathrm{C}=\mathrm{C}$ reduction by $\mathrm{NaBH}_{4}$.

reduction of $(E)$-ethyl-3-phenylbut-2-enoate into $(R)$-ethyl-3phenylbutanoate 52 by $\mathrm{NaBH}_{4}$, using chiral azabis(oxazoline) ligands 53-54 and a mixture of the glycerol-based ether BTFEP (1,3-bis(2,2,2-trifluoroethoxy)propan-2-ol) and ethanol as solvent (Scheme 33). ${ }^{72}$ When compared with its homologue 53, ligand 54 conferred a higher stability to the resulting catalytic system, thus leading to a better conversion, selectivity and recyclability. Interestingly, the catalytic performances of these cobalt(II)/azabis(oxazoline) systems in BTFEP/EtOH surpassed by far those achieved using the ionic liquid [BMIM] $\left[\mathrm{PF}_{6}\right]$ as solvent.

In the last few decades, metal-catalyzed transfer hydrogenation (TH) reactions from 2-propanol to unsaturated compounds have emerged as an efficient reduction method of organic substrates such as ketones, aldehydes, imines and olefins. ${ }^{73}$ Like 2-propanol, glycerol can also act as a solvent and hydrogen donor in $\mathrm{TH}$ reactions. Interest in $\mathrm{TH}$ processes from glycerol relates also with the concomitant formation of dihydroxyacetone (DHA), the expected oxidized form of glycerol, ${ }^{74}$ due to the industrial relevance of this chemical. ${ }^{75}$ The first report on $\mathrm{TH}$ in glycerol, published by Crotti and co-workers in 2009, examined the reduction of acetophenone by the iridium(I) derivatives $[\operatorname{Ir}(1,5$-hexadiene $)(\mathrm{N}-\mathrm{N})][\mathrm{Cl}]$ $\left(\mathrm{N}-\mathrm{N}=3,4,7,8\right.$-tetramethyl-1,10-phenanthroline $\left(\mathrm{Me}_{4}\right.$ phen $)$, 4,7-dimethyl-1,10-phenanthroline ( $\left.\mathrm{Me}_{2} \mathrm{phen}\right), 4,4^{\prime}$-dimethyl2,2'-bipyridine ( $\mathrm{Me}_{2}$ bipy), 2,2'-bipyridine (bipy)). ${ }^{76}$

The highest rate was achieved by employing [ $\operatorname{Ir}(1,5-$ hexadiene)( $\mathrm{Me}_{2}$ phen) $][\mathrm{Cl}]$ associated with $\mathrm{K}_{2} \mathrm{CO}_{3}$ at $100{ }^{\circ} \mathrm{C}$, but conversion in 1-phenylethanol was quite modest $(39 \%)$ (Scheme 34). In addition, authors observed the gradual decomposition of DHA, probably favoured by the presence of a base and the high temperature employed. In order to minimize the DHA decomposition, Crotti and co-workers also explored the ability of the iridium(I) complex 55 (Fig. 4),

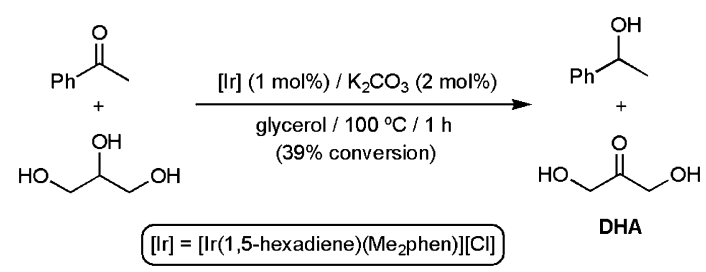

Scheme 34 Transfer hydrogenation of acetophenone in glycerol. 


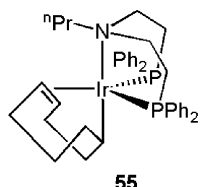

Fig. 4 Structure of the iridium(I) complex 55.

previously described as an efficient catalyst for $\mathrm{TH}$ reactions under base-free conditions in isopropanolic media, ${ }^{77}$ to promote the reduction of acetophenone in glycerol. ${ }^{78}$ Unfortunately, 55 turned out to be almost inactive (yields $<8 \%$ ). In contrast, when benzaldehyde, a more reactive substrate, was used as starting material it could be reduced to benzyl alcohol under these base-free conditions, albeit with moderate conversion (up to $46 \%$ ). Once again, despite the absence of a base, DHA still underwent degradation, with its final proportion being well below than that of benzyl alcohol (12-24\% vs. $18-46 \%)^{78}$

The hydrogen transfer from glycerol to benzaldehyde was also explored using a catalytic system composed of the ruthenium dimer $\left[\left\{\mathrm{RuCl}(\mu-\mathrm{Cl})\left(\eta^{6}-p \text {-cymene }\right)\right\}_{2}\right]$ and $\mathrm{KOH}$ (1 $\mathrm{mol} \%$ of $\mathrm{Ru}, 12 \mathrm{~mol} \%$ of base).$^{79}$ Both conventional heating $\left(70{ }^{\circ} \mathrm{C}\right)$ and $\mathrm{MW}$ irradiation (domestic oven, $900 \mathrm{~W}$ ) led to moderate yields in benzyl alcohol (33-45\%), and complete transformation of benzaldehyde could only be achieved by increasing the ruthenium loading to $25 \mathrm{~mol} \%{ }^{79 a}$

Reduction of olefins through $\mathrm{TH}$ processes in glycerol proved to be more satisfactory than reduction of carbonyl compounds. Thus, palladium supported on carbon $(0.2-0.3$ $\mathrm{mol} \% \mathrm{Pd}$ ) was found to hydrogenate quantitatively cyclohexene or styrene after 5-9 hours of heating at $70{ }^{\circ} \mathrm{C}$ in pure glycerol (Scheme 35). ${ }^{79 a}$ However, we must note that bulky olefins (i.e. stilbene and 1,1-diphenyl ethylene) and linear aliphatic alkenes (i.e. 1-hexene and 1-octene) were only partially reduced through this methodology (7-35\% yields). ${ }^{80}$

The reductive etherification of glycerol with carbonyl compounds depicted in Scheme 36 is another example of a catalytic process in which the glycerol acts both as a solvent

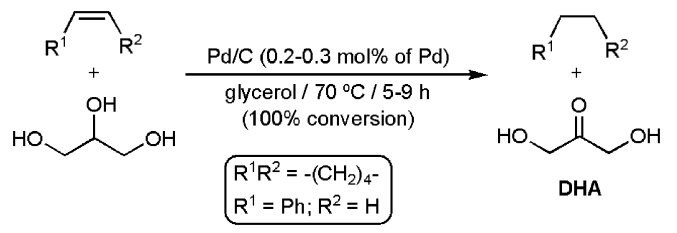

Scheme 35 Pd-catalyzed transfer hydrogenation of olefins in glycerol.

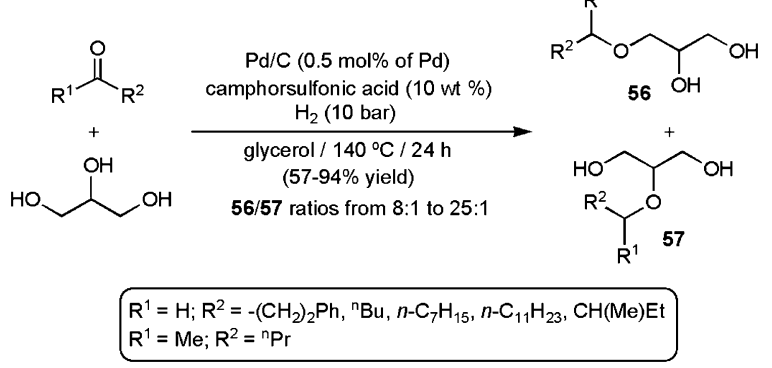

Scheme 36 Reductive etherification of glycerol. and reagent. This coupling between an aldehyde (or a ketone) and glycerol, promoted by $\mathrm{Pd} / \mathrm{C}$ and camphorsulfonic acid under $\mathrm{H}_{2}$ atmosphere, offers an easy entry to glycerol monoethers 56-57. ${ }^{81}$ Interestingly, despite the similar $\mathrm{p} K_{\mathrm{a}}$ values of the different hydroxyl groups in glycerol, 1- $O$-alkylation occurred preferentially, thus generating ethers $\mathbf{5 6}$ as the major reaction products. This high selectivity is specific to glycerol since related etherification reactions of 1,2-propanediol, a diol with both primary and secondary hydroxyl functions, gave rise to $1: 1$ mixtures of the two possible regioisomers, i.e. 1-O-alkyl and 2-O-alkyl ethers. Concerning the mechanism of these catalytic reactions, the authors demonstrated that 5- and 6-membered cyclic acetals are first formed from the starting aldehyde and glycerol, and then they are reduced with hydrogen to generate the final acyclic ethers.

Glycerol-based acetals and ketals are valuable chemical intermediates, ${ }^{82}$ and the development of efficient and selective routes of access is of particular interest. Glycerol acetalization can be promoted by conventional acid catalysts, however such procedures are environmentally unfriendly due to extensive salt formation, and they suffer from a lack of selectivity towards the two possible regioisomers, i.e. the five-membered cyclic acetal (1,3-dioxolane 58) and the six-membered one (1,3-dioxane 59). In contrast, it has been recently demonstrated that the iridium dimer $\left[\left\{\operatorname{Ir}(\mu-\mathrm{Cl}) \mathrm{Cl}\left(\eta^{5}-\mathrm{C}_{5} \mathrm{Me}_{5}\right)\right\}_{2}\right]$ catalyzes the glycerol acetalization with acetone in good yield (75\%) and excellent selectivity (98\%) towards the corresponding 1,3dioxolane 58 (Scheme 37). ${ }^{83}$ Comparable results were also obtained with cyclohexanone, but the involvement of more sterically hindered ketones resulted in a drop of the conversion (only $14 \%$ for $\mathrm{R}^{1}=\mathrm{R}^{2}={ }^{\mathrm{i}} \mathrm{Pr}$ ). The acetalization with acetophenone, an unsymmetrical ketone, exhibited once again a good regioselectivity ( $96 \%$ of 58), but a total lack of diastereoselectivity (cis/trans ratio $=1: 1$ ). As expected, aldehydes showed higher reactivity than ketones (yields up to $87 \%$ ), albeit with a slightly lower regioselectivity (78-82\%).

Cycloisomerization of $(Z)$-enynols represents an appealing route for the construction of furan rings due to its atomeconomical nature. ${ }^{84}$ However, despite its synthetic interest, efforts devoted to develop this process in a green media have been scarce. ${ }^{85}$ Recently, the heteroannulation of (Z)-2-en-4yn-1-ol derivatives $\mathbf{6 0}$ into furans $\mathbf{6 1}$ has been conveniently performed in glycerol using the hydrophilic palladium(II) catalyst $c i s-\left[\mathrm{PdCl}_{2}(\mathrm{DAPTA})_{2}\right] \quad$ (Scheme 38). ${ }^{86}$ Although slightly higher activities were observed in aqueous medium, catalyst recycling after extraction of the product with diethyl ether was much more effective in glycerol. Thus, while the

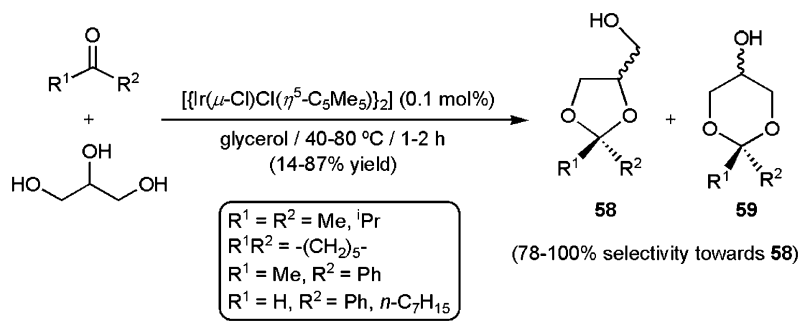

Scheme 37 Ir-catalyzed glycerol acetalization with carbonyl compounds. 


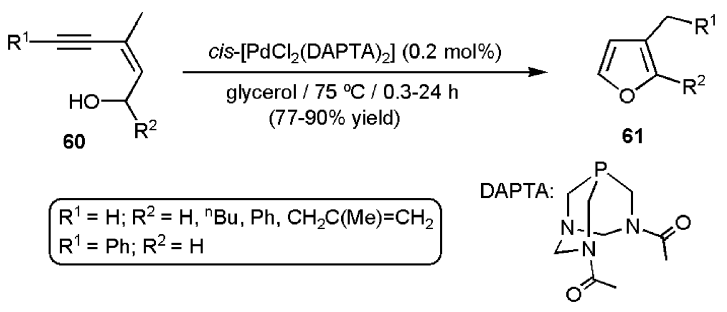

Scheme 38 Palladium-catalyzed cycloisomerization of ( $Z$ )-enynols.

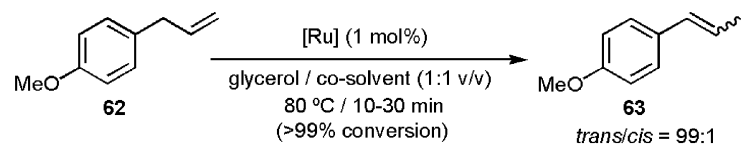

Co-solvent: $\mathrm{EtOH}$ or $\mathrm{MeOH}$

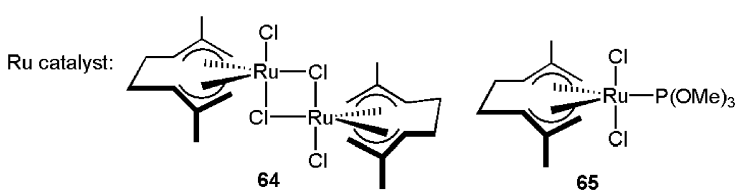

Scheme 39 Ru-catalyzed isomerization of estragole into anethole.

performances of the aqueous solution decreased rapidly, allowing only five consecutive runs, the catalytic behavior of the glycerolic phase was maintained during 17 runs, leading to cumulative TON values up to 8190 , which are the highest reported up to date for this catalytic transformation.

trans-Anethole $\mathbf{6 3}$ is a relevant compound with important applications in the cosmetic industries and as a food and beverage additive. According to current food regulatory instructions, the cis-anethole content is limited to $1 \%$ for human uses due to its toxicity and organoleptic properties. Hence, the search for highly trans-selective formation of anethole represents a challenge for synthetic chemists. In this context, a green protocol based on the isomerization of estragole 62 into anethole has been designed in glycerolic media employing different ruthenium(Iv) catalysts (Scheme 39) ${ }^{87}$ Best results were accomplished with the dimeric precursor 64 and the mononuclear derivative $\mathbf{6 5}$ in glycerol/ $\mathrm{EtOH}$ or glycerol/MeOH mixtures which allowed full conversions in short times and, most importantly, with high trans-selectivities (99\%). Similar results were also obtained using water/MeOH or water/EtOH solvent systems, but catalyst recycling was again more effective from the glycerolic mixtures.

Coupling reactions of vinyl bromides with diaryl diselenides have also been studied using glycerol as the reaction medium (Scheme 40). ${ }^{88}$ Seleniations proceeded efficiently in the

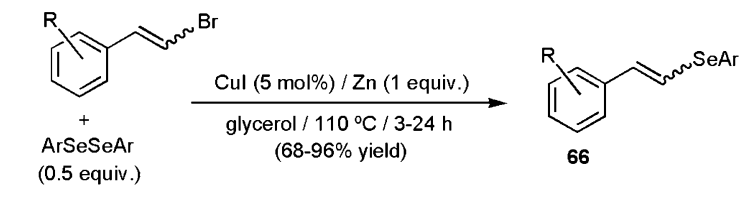

$\mathrm{Ar}=\mathrm{Ph} ; \mathrm{R}=\mathrm{H}, 4-\mathrm{OMe}, 4-\mathrm{Me}, 4-\mathrm{Cl}, 2-\mathrm{OMe}, 3-\mathrm{OMe}, 3,5-(\mathrm{OMe})_{2}$

$\mathrm{Ar}=4-\mathrm{C}_{6} \mathrm{H}_{4} \mathrm{OMe}, 4-\mathrm{C}_{6} \mathrm{H}_{4} \mathrm{Me}, 4-\mathrm{C}_{6} \mathrm{H}_{4} \mathrm{Cl}, 2-\mathrm{C}_{6} \mathrm{H}_{4} \mathrm{Me}, 3-\mathrm{C}_{6} \mathrm{H}_{4} \mathrm{CF}_{3}$, 2-naphthyl; $\mathrm{R}=\mathrm{H}$

Scheme 40 Copper(I)-catalyzed seleniation of vinyl bromides in glycerol.

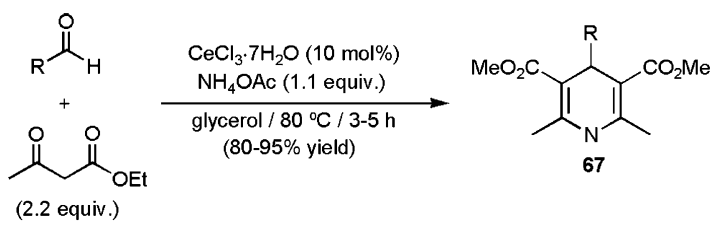

$\mathrm{R}=\mathrm{Ph}, 4-\mathrm{C}_{6} \mathrm{H}_{4} \mathrm{NO}_{2}, 4-\mathrm{C}_{6} \mathrm{H}_{4} \mathrm{NMe}_{2}, 3-\mathrm{C}_{6} \mathrm{H}_{4} \mathrm{Cl}, 3,4,5-\mathrm{C}_{6} \mathrm{H}_{2}(\mathrm{OMe})_{3}$,
$(E)-\mathrm{CH}=\mathrm{CHPh}, \mathrm{Bn},{ }^{,} \mathrm{Pr}, n-\mathrm{C}_{10} \mathrm{H}_{21}, 2$-pyridyl, 2-furyl

Scheme 41 Hantzsch synthesis of pyridines in glycerol.

presence of $5 \mathrm{~mol} \%$ of $\mathrm{CuI}$ and zinc dust, and were operative with several diaryl diselenides and a variety of substituted aromatic vinyl bromides, with cis- or trans-disposition on the $\mathrm{C}=\mathrm{C}$ bond. Interestingly, the stereochemistry of the starting products was mainly retained in the final vinyl selenides $\mathbf{6 6}$. Following a similar methodology, phenyl styryl telluride has been synthesized from diphenyl ditelluride. We note also that the catalytic system could be recovered, after extraction of the products with ethyl acetate, and reused 4 times with only a slight decrease in the activity.

In recent years, considerable attention has been paid to the synthesis of 1,4-dihydropyridines owing to their significant biological activities. ${ }^{89}$ One of the most reliable methodologies is the Hantzsch reaction, a one-pot three-component process, which involves the coupling between an aldehyde, two equivalents of a $\beta$-ketoester and an ammonium salt. In this context, Narsaiah and Nagaiah have recently developed a procedure to prepare Hantzsch pyridines in glycerol. ${ }^{90}$ Thus, as shown in Scheme 41, using $10 \mathrm{~mol}^{\%}$ of $\mathrm{CeCl}_{3}$ as a catalyst, a variety of electron-rich or electron deficient aromatic-, heteroaromatic- or aliphatic-aldehydes were efficiently transformed into 1,4-dihydropyridines $\mathbf{6 7}$ by coupling with ethyl acetoacetate and ammonium acetate.

\section{Biocatalysis}

Biocatalysis plays an important role within the Green Chemistry context, since it usually provides highly chemo- regioand stereoselective synthetic routes under mild conditions. ${ }^{91}$ Although the natural solvent for enzymes is water, the hydrophobic character of most of the organic compounds has made almost mandatory the use of partly or fully nonaqueous environments. However, it is well-documented that enzymes are denatured in the presence of organic solvents, and that the specific catalytic activities of enzymes that are stable in organic media are generally lower than those in aqueous systems. ${ }^{92}$ In this sense, the ability of glycerol to mimic the effect of water preserving enzyme structure, ${ }^{92}$ makes this solvent an appropriate candidate for biocatalysis.

In 2006, Wolfson and co-workers reported the first biocatalytic transformation in pure glycerol, accomplishing successfully the asymmetric reduction of methyl acetoacetate with both free (FBY) and immobilized (IBY; alginate beads) baker's yeast. ${ }^{93}$ As illustrated in Table 3, IBY showed a higher catalytic activity than FBY, while the enantioselectivity of the product, (S)-methyl 3-hydroxybutyrate, was very high ( $>95 \%$ ee) with both catalysts (entry 1). The higher performance of IBY was attributed to the presence of residual water, which 
Table 3 Enantioselective reduction of methyl acetoacetate with baker's yeast in glycerol $^{a}$

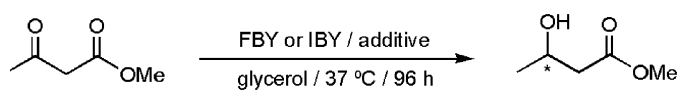

\begin{tabular}{llllll}
\hline Entry & Additive & FBY $(\%)$ & ee $(\%)$ & IBY $(\%)$ & ee $(\%)$ \\
\hline 1 & None & 61 & $>99(S)$ & 87 & $>99(S)$ \\
2 & Water $^{b}$ & 73 & $97(S)$ & 94 & $97(S)$ \\
3 & Glucose & 71 & $>99(S)$ & 96 & $>99(S)$ \\
4 & Sucrose & 75 & $>99(S)$ & 99 & $>99(S)$ \\
5 & Ethanol & 67 & $95(S)$ & 90 & $>99(S)$
\end{tabular}

${ }^{a}$ Reactions performed at $37^{\circ} \mathrm{C}$ for $96 \mathrm{~h}$ using $1 \mathrm{~g}$ of substrate, $50 \mathrm{~mL}$ of glycerol, $10 \mathrm{~g}$ of FBY or $50 \mathrm{~g}$ of IBY (generated from $10 \mathrm{~g}$ of FBY) and $5 \mathrm{~g}$ of additive. ${ }^{b} 5 \mathrm{wt} \%$.

remained inside the IBY beads during their preparation. In accord with this, the addition of $5 \mathrm{wt} \%$ of water to glycerol increased the activity without changing significantly the enantioselectivity (entry 2 vs. 1). Addition of various hydrogen sources, such as glucose (entry 3), sucrose (entry 4) or ethanol (entry 5), equally increased the activity (up to $99 \%$ conversion), while keeping the high enantioselectivity. Using IBY as the catalyst and sucrose as the additive, good results were also obtained in the asymmetric reduction of ethyl acetoacetate, i.e. $99 \%$ conversion after $48 \mathrm{~h}$ with $>99 \%$ ee. However, we must note that, under the same reaction conditions, the activity of IBY towards the aliphatic prochiral ketones 2-octanone and 2-butanone was much lower (up to $22 \%$ conversion after $96 \mathrm{~h}$ with $>97 \%$ ee). ${ }^{93}$

Remarkably, although higher activities were observed when these reduction reactions were performed in aqueous medium, the use of glycerol as solvent enabled a more efficient product extraction, since glycerol does not form emulsions with the extracting solvent (ethyl acetate, diethyl ether, $n$-hexane and dichloromethane were evaluated). ${ }^{93,94}$

Table 4 Influence of organic co-solvents in the asymmetric bioreduction of $2^{\prime}$-chloroacetophenone ${ }^{a}$<smiles>CC(=O)c1ccccc1Cl</smiles>

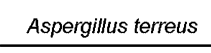
solvent $/ 32^{\circ} \mathrm{C} / 48 \mathrm{~h}$

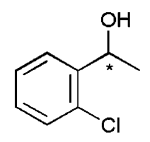

\begin{tabular}{llll}
\hline Entry & Solvent & Yield $(\%)$ & ee $(\%)$ \\
\hline 1 & PBS & 24 & $65(S)$ \\
2 & PBS-glycerol $(9: 1)$ & 49 & $92(S)$ \\
3 & PBS-glycerol $(4: 1)$ & 44 & $>99(S)$ \\
4 & PBS-DMSO $(9: 1)$ & 51 & $>99(S)$ \\
5 & PBS-DMSO $(4: 1)$ & 10 & $>99(S)$ \\
6 & PBS-acetonitrile $(9: 1)$ & 9 & - \\
7 & PBS-acetonitrile $(4: 1)$ & - & - \\
8 & PBS-toluene $(9: 1)$ & 4 & - \\
9 & PBS-toluene $(4: 1)$ & $<1$ & - \\
10 & PBS-diethyl ether $(9: 1)$ & 4 & - \\
11 & PBS-diethyl ether $(4: 1)$ & 3 & - \\
12 & PBS-THF $(9: 1)$ & 2 & - \\
13 & PBS-THF $(4: 1)$ & 2 &
\end{tabular}

${ }^{a}$ Reactions performed at $32{ }^{\circ} \mathrm{C}$ for $48 \mathrm{~h}$ using $3.0 \mathrm{~g}$ of fungal cells, $20 \mu \mathrm{L}$ of substrate and $50 \mathrm{~mL}$ of solvent. $\mathrm{PBS}=$ phosphate buffer solution $\left(\mathrm{Na}_{2} \mathrm{HPO}_{4} / \mathrm{KH}_{2} \mathrm{PO}_{4} ; \mathrm{pH} 7\right)$.
Studies by Andrade and co-workers have also demonstrated the utility of glycerol as co-solvent for biocatalytic transformations in aqueous solution. Thus, in the enantioselective bioreduction of $2^{\prime}$-chloroacetophenone by cells of Aspergillus terreus in phosphate buffer solution $(\mathrm{pH} 7)$, they observed remarkable yield and enantioselectivity improvements by adding variable amounts of glycerol (entries 2 and 3 vs. 1 in Table 4). ${ }^{95}$ As shown in Table 4, such improvements were in general not observed using other water-organic solvent mixtures (entries 4-13). Three factors have been evoked to explain the beneficial effect of glycerol in this reaction: (i) it improves the solubility of the substrate, (ii) unlike the other organic solvents, it generates a homogeneous medium in combination with water that avoids mass transfer limitations facilitating the enzyme-substrate interactions, and (iii) it stabilizes the protein native structure and prevents its denaturation, thus preserving the enzymatic activity. We note that similar positive results were obtained in the bioreduction of other ortho-, meta- and para-substituted halo-acetophenones $(\mathrm{F}, \mathrm{Cl}, \mathrm{Br}) .{ }^{95}$ In addition, the synthetic utility of the process was confirmed by performing the catalytic reactions at a preparative scale, which delivered the desired optically active alcohols in high isolated yields (up to $80 \%$ with $95-99 \%$ ee).

The higher ability of glycerol $v s$. water to dissolve organic compounds has also been exploited to facilitate the hydrolytic kinetic resolution of racemic styrene oxide at high substrate concentrations. ${ }^{96}$ Thus, using the recombinant Pichia pastoris yeast which expresses the epoxide hydrolase gene of Rhodotorula glutinis as the biocatalyst, enantiopure $(S)$-styrene oxide $(98 \%$ ee) could be obtained in $41 \%$ yield (maximum yield $=50 \%$ ) from $1.8 \mathrm{M}$ racemic styrene oxide, after $24 \mathrm{~h}$ at $4{ }^{\circ} \mathrm{C}$, by adding $40 \%$ $(\mathrm{v} / \mathrm{v})$ of the surfactant Tween 20 and $5 \%(\mathrm{v} / \mathrm{v})$ of glycerol to the $\mathrm{KH}_{2} \mathrm{PO}_{4}$ buffer ( $\mathrm{pH}$ 8.0). Note that, in the absence of glycerol, the recombinant cells only catalyzed the kinetic resolution efficiently at concentrations below $1.3 \mathrm{M}(0.526 \mathrm{M}$ in the absence of both Tween 20 and glycerol).

The utility of triacetin as green solvent and acyl donor for lipase-catalyzed kinetic resolution of racemates has also been recently demonstrated by Dlugy and Wolfson. ${ }^{97}$ Thus, as shown in Scheme 42, they successfully performed the kinetic resolution of representative secondary alcohols and amines 68 in triacetin using Candida antarctica lipase B immobilized on acrylic resin (iCAL-B). Full conversions (50\%) and excellent enantioselectivities (97-99\% ee) were in all cases reached at $80{ }^{\circ} \mathrm{C}$ employing an enzyme to substrate $(\mathrm{E} / \mathrm{S})$ ratio of $16.5 \mathrm{~g} \mathrm{~mol}^{-1}$. In the course of the alcoholysis process, glycerol

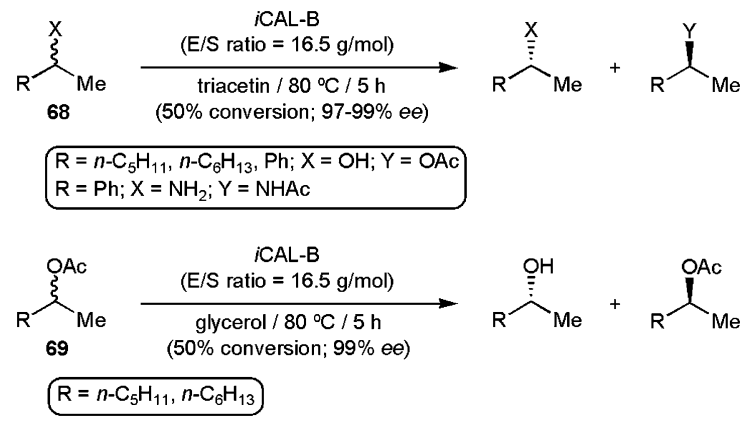

Scheme 42 Kinetic resolutions using triacetin and glycerol. 
diacetate, glycerol monoacetate and glycerol are formed as by-products. However, their high solubility in triacetin allowed the easy separation of the desired alcohol (or amine) and ester (or amide) enantiomers from the crude reaction mixture by simple extraction with diethyl ether. In the same work, efficient kinetic resolution of 2-heptyl acetate and 2-octyl acetate racemates 69 could also be achieved using glycerol as the solvent and acyl-acceptor (Scheme 42). ${ }^{97}$ The effective resolution of a racemic mixture of 2-pentyl acetate with $i$ CAL-B in glycerol was similarly achieved. ${ }^{38}$

Triacetin was also employed as solvent and acyl donor in the transesterification of isoamyl alcohol $\mathbf{3 9}$ into isoamyl acetate 40 (see Scheme 26). ${ }^{98}$ Both free (CAL-B) and immobilized Candida antarctica lipase B ( $i \mathrm{CAL}-\mathrm{B})$ were able to promote efficiently the transesterification process, with the latter showing a higher efficiency $(73 \%$ of conversion after $5 \mathrm{~h}$ at $80{ }^{\circ} \mathrm{C}$ ). At the end of the reaction, $\mathbf{4 0}$ could be easily separated from the reaction mixture by extraction with petroleum ether, and the immobilized lipase was recovered by simple filtration and re-used three additional times without significant loss of its efficiency.

Deep eutectic solvents (DESs) have recently emerged as promising reaction media for biocatalysis. ${ }^{99}$ In this context, using the transesterification of ethyl valerate with 1-butanol as model reaction, the activities of selected lipases in different DESs based on choline chloride $(\mathrm{ChCl})$ or ethylammonium chloride (EAC) mixtures with the organic hydrogen-bond donors acetamide (Acet), urea (U), malonic acid (MA), ethylene glycol (EG) or glycerol (Gly) were evaluated by Kazlauskas and co-workers. ${ }^{100}$ As shown in Table 5, all the enzymes tested showed similar or higher activities to that shown in toluene (entry 9) when the glycerol-based deep eutectic mixture ChCl:Gly (entry 3) was used as solvent

Table 5 Lipase-catalyzed transesterification of ethyl valerate with 1-butanol in DESs and toluene ${ }^{a}$

\begin{tabular}{|c|c|c|c|c|}
\hline Solvent & $i \mathrm{CAL}-\mathrm{B}^{b}$ & CAL-B ${ }^{b}$ & CAL-A $^{b, c}$ & $\mathrm{PCL}^{b, d}$ \\
\hline ChCl:Acet & 23 & 96 & 0.5 & 0.0 \\
\hline ChCl:EG & $11(99)$ & $32(93)$ & 3.0 & 0.2 \\
\hline ChCl:Gly & 96 & 96 & 70 & 22 \\
\hline ChCl:MA & 30 & 58 & 0.7 & 0.0 \\
\hline ChCl:U & 93 & 99 & 1.6 & 0.8 \\
\hline EAC:Acet & 63 & 92 & 2.7 & 0.0 \\
\hline EAC:EG & $23(54)$ & $33(79)$ & 20 & 0.0 \\
\hline EAC:Gly & 93 & 91 & 2.1 & 0.5 \\
\hline Toluene & 92 & 92 & 76 & 5.0 \\
\hline
\end{tabular}

${ }^{a}$ Reactions performed at $60{ }^{\circ} \mathrm{C}$ for $24 \mathrm{~h}$ using $40 \mathrm{mM}$ ethyl valerate, $400 \mathrm{mM} \mathrm{1-butanol}$ and $10 \mathrm{mg} \mathrm{cm}^{-3}$ of the corresponding enzyme.

${ }^{b}$ Percentage conversions of ethyl valerate to butyl valerate are given $(\%)$. Number in parentheses is the percentage conversion including the side reaction with the ethylene glycol component of the deep eutectic solvent. No side reactions were observed in the rest of the cases. ${ }^{c} \mathrm{CAL}-\mathrm{A}=$ lyophilized Candida antarctica lipase A. ${ }^{d} \mathrm{PCL}=$ lyophilized Pseudomonas cepacia lipase (recently reclassified as Burkholderia cepacia).

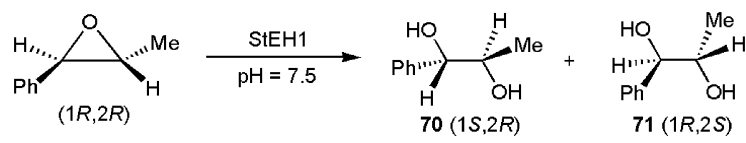

Scheme 43 StEH1-catalyzed hydrolysis of $(1 R, 2 R)$-2-methylstyrene oxide.

(iCAL-B and CAL-B showed also a remarkable activity in EAC:Gly; entry 8). Remarkably, contrary to the case of ethylene glycol (entries 2 and 7), competence of glycerol with 1-butanol in the transesterification process was not observed. In addition, after incubation of $i$ CAL-B in either toluene or $\mathrm{ChCl}$ :Gly for $18 \mathrm{~h}$ at $60{ }^{\circ} \mathrm{C}$, its activity dropped by $12 \%$ in toluene, compared to that observed before incubation, and only by $5 \%$ in $\mathrm{ChCl}$ :Gly, thus demonstrating the higher long-term stability of the enzyme in this alternative reaction medium. ${ }^{100 c} i$ CAL-B-catalyzed aminolysis of ethyl valerate with 1-butylamine could also be conveniently performed in $\mathrm{ChCl}$ :Gly with a rate and conversion similar again to that reached in toluene. ${ }^{100 a, b}$

The deep eutectic mixture $\mathrm{ChCl}$ :Gly can also be used as a suitable co-solvent for biocatalytic transformations in aqueous solution. In this sense, the rate of esterase-catalyzed hydrolysis of $p$-nitrophenol acetate in BES buffer ( $N, N$-bis(2-hydroxyethyl)-2-aminoethanesulfonic acid and its sodium salt) increased moderately upon addition of $10 \mathrm{vol} \%$ of $\mathrm{ChCl}$ :Gly (three-fold increase for pig liver esterase and Rhizopus oryzae esterase and a $25 \%$ increase for Pseudomonas fluorescens esterase), while an impressive 20-fold increase in conversion was observed in the EHAD1-catalyzed hydrolysis of styrene oxide $($ EHAD1 = epoxide hydrolase AD1 from Agrobacterium radiobacter $){ }^{100}$ The effect of $\mathrm{ChCl}$ :Gly in the catalytic hydrolysis of $(1 S, 2 S)$ - and $(1 R, 2 R)$-2-methylstyrene oxide was also evaluated using the Solanum tuberosum epoxide hydrolase 1 (StEH1). ${ }^{101}$ In this case, enzyme function was not significantly affected by the presence of the glycerol-based DES. However, it is of note that it was able to enhance the regioselectivity of the hydrolysis of the $(1 R, 2 R)$ enantiomer, favouring the epoxide ring opening at the benzylic carbon, as compared to the phosphate buffer-only system $(\mathbf{7 0} / 71$ ratio $=2.33$ vs. 1.35; Scheme 43). Unfortunately, no explanation was given for this solvent-effect on the regioselectivity.

\section{Conclusions}

This Feature Article has outlined the utilization of glycerol and some of its derivatives as green reaction solvents for synthetic organic chemistry, an emerging research field that has as main objective the valorization of a waste generated by the biodiesel industry. The current availability of glycerol on a large scale and at a low cost, combined with its intrinsic properties, i.e. no toxicity, no flammability, obtaining from renewable sources and biodegradability, makes it an ideal candidate to develop greener synthetic processes. However, despite all these considerations, problems associated with its high viscosity, which could provoke poor substrate diffusion in the medium, and the presence of three reactive and metal-coordinating hydroxyl groups should be taken into account prior to its utilization as solvent for a particular reaction. Extraction of 
highly polar reaction products from glycerol is also a problem that needs to be solved prior to practical uses.

Solvent properties of glycerol can be tailored, tuned and adjusted according to the requirements of each reaction by chemical modification of its structure, thus allowing to overcome some of the above-mentioned drawbacks. However, synthetic routes must be improved since most of the glycerolbased solvents presently available are synthesized through very costly processes.

In summary, although much effort has to be made in the future to extend the use of these alternative solvent systems, the numerous publications appeared in the last five years reveal that this field is of major interest to the chemical community, and the authors hope that this comprehensive account will stimulate further work.

\section{Acknowledgements}

Financial support from the Spanish MICINN (Projects CTQ2006-08485/BQU, CTQ2010-14796/BQU and CSD200700006) is gratefully acknowledged. B.L.-B. thanks FICYT of Asturias (PCTI-Severo Ochoa program) and J.F. thanks MEC of Spain and the European Social Fund (FPU program) for the award of $\mathrm{PhD}$ grants.

\section{Notes and references}

1 (a) P. Kruger, Alternative Energy Resources: The Quest for Sustainable Energy, John Wiley \& Sons, Hoboken, 2006; (b) N. Armaroli and V. Balzani, Angew. Chem., Int. Ed., 2007, 46, 52; (c) D. A. Coley, Energy and Climate Change Creating a Sustainable Future, John Wiley \& Sons, Chichester, 2008; (d) F. H. Cocks, Energy Demand and Climate: Change Issues and Resolutions, Wiley-VCH, Weinheim, 2009.

2 (a) W. H. Kemp, Biodiesel: Basics and Beyond, Azlext Press, Ontario, 2006; (b) A. Demirbas, Biodiesel: A Realistic Fuel Alternative for Diesel Engines, Springer-Verlag, London, 2008; (c) G. Pahl, Biodiesel: Growing a New Energy Economy, Chelsea Green Publishing, White River Junction, 2008; (d) The Biodiesel Handbook, ed. G. Knothe, J. Krahl and J. Van Gerpen, AOCS Publishing, Urbana, 2010; (e) A. Hoogendoorn and H. van Kasteren, Transportation Biofuels Novel Pathways for the Production of Ethanol, Biogas and Biodiesel, RSC Publishing, Cambridge, 2010.

3 C.-H. Zhou, J. N. Beltramini, Y.-X. Fan and C. Q. Lu, Chem. Soc. Rev., 2008, 37, 527.

4 In addition to the biodiesel industry, glycerol is also formed as a by-product in several processes based on the conversion of cellulose and lignocellulose. See, for example: R. Palkovits, K. Tajvidi, A. M. Ruppert and J. Procelewska, Chem. Commun., 2011, 47, 576.

5 Data in Fig. 1 were taken from the Natural Chem Group: http://www.naturalchem.com/TheGlycerinePlant.html (accessed in January, 2011).

6 M. Pagliaro and M. Rossi, The Future of Glycerol: New Usages for a Versatile Raw Material, RSC Publishing, Cambridge, 2008.

7 (a) M. Pagliaro, R. Ciriminna, H. Kimura, M. Rossi and C. D. Pina, Angew. Chem., Int. Ed., 2007, 46, 4434; (b) A. Corma, S. Iborra and A. Velty, Chem. Rev., 2007, 107, 2411; (c) D. T. Johnson and K. A. Taconi, Environ. Prog., 2007, 26, 338; (d) A. Behr, J. Eilting, K. Irawadi, J. Leschinski and F. Lindner, Green Chem., 2008, 10, 13; (e) F. Jérôme, Y. Pouilloux and J. Barrault, ChemSusChem, 2008, 1, 586; (f) G. P. da Silva, M. Mack and J. Conteiro, Biotechnol. Adv., 2009, 27, 30; $(g)$ C. J. A. Mota, C. X. A. da Silva and V. L. C. Gonçalves, Quim. Nova, 2009, 32, 639; (h) M. Pagliaro, R. Ciriminna, H. Kimura, M. Rossi and C. D. Pina, Eur. J. Lipid Sci. Technol., 2009, 111, 788; (i) P. F. F. Amaral, T. F. Ferreira,
G. C. Fontes and M. A. Z. Coelho, Food Bioprod. Process., 2009, 87, 179.

8 For recent reviews on this topic, see: (a) P. D. Vaidya and A. E. Rodrigues, Chem. Eng. Technol., 2009, 32, 1463; (b) S. Adhikari, S. D. Fernando and A. Haryanto, Energy Convers. Manage., 2009, 50, 2600.

9 For a recent review on this topic, see: N. Rahmat, A. Z. Abdullah and A. R. Mohamed, Renewable Sustainable Energy Rev., 2010, 14, 987.

10 (a) P. T. Anastas, J. C. Warner, Green Chemistry Theory and Practice, Oxford University Press, Oxford, 1998; (b) A. S. Matlack, Introduction to Green Chemistry, Marcel Dekker, New York, 2001; (c) Handbook of Green Chemistry and Technology, ed. J. H. Clark and D. J. Macquarrie, Blackwell Publishing, Abingdon, 2002; (d) M. Lancaster, Green Chemistry: An Introductory Text, RSC Editions, Cambridge, 2002; (e) M. Poliakoff, J. M. Fitzpatrick, T. R. Farren and P. T. Anastas, Science, 2002, $297,807$.

11 Studies performed by GlaxoSmithKline workers suggest that close attention to the effective use and reuse of solvents is likely to result in the greatest improvements to making chemical processes "greener": A. D. Curzons, D. J. C. Constable, D. N. Mortimer and V. L. Cunningham, Green Chem., 2001, 3, 1.

12 See, for example: (a) J. M. DeSimone, Science, 2002, 297, 799; (b) W. M. Nelson, Green Solvents for Chemistry: Perspectives and Practice, Oxford University Press, New York, 2003; (c) J. H. Clark and S. J. Taverner, Org. Process Res. Dev., 2007, 11, 149; (d) F. M. Kerton, Alternative Solvents for Green Chemistry, RSC Publishing, Cambridge, 2009.

13 For leading references in this field, see: (a) C. J. Li and T. H. Chan, in Comprehensive Organic Reactions in Aqueous Media, John Wiley \& Sons, New Jersey, 2007; (b) Organic Reactions in Water: Principles Strategies, and Applications, ed. U. M. Lindstrom, Blackwell Publishing Ltd., Oxford, 2007; (c) Aqueous-Phase Organometallic Catalysis: Concepts and Applications, ed. B. Cornils and W. A. Herrmann, Wiley-VCH, Weinheim, 1998; (d) F. Joó, Aqueous Organometallic Catalysis, Kluwer, Dordrecht, 2001; (e) Some examples of water-based processes in the pharmaceutical industry can be found in: B. W. Cue and J. Zhang, Green Chem. Lett. Rev., 2009, 2, 193.

14 Y. Gu and F. Jérôme, Green Chem., 2010, 12, 1127.

15 See, for example: (a) Microwave Heating as a Tool for Sustainable Chemistry, ed. N. E. Leadbeater, CRC Press, Boca Raton, 2011; (b) Aqueous Microwave Assisted Chemistry, ed. V. Polshettiwar and R. S. Varma, RSC Publishing, Cambridge, 2010.

16 See, for example: (a) J. C. Thompson and B. B. He, Appl. Eng. Agric., 2006, 22, 621; (b) L. Bournay, D. Casanove, B. Delfort, G. Hillion and J. A. Chodorge, Catal. Today, 2005, 106, 190.

17 J. I. García, H. García-Marín, J. A. Mayoral and P. Pérez, Green Chem., 2010, 12, 426.

18 See, for example: P. Ferreira, I. M. Fonseca, A. M. Ramos, J. Vital and J. E. Castanheiro, Catal. Commun., 2009, 10, 481, and references cited therein.

19 See, for example: (a) J. Deutsch, A. Martin and H. Lieske, J. Catal., 2007, 245, 428; (b) V. R. Ruiz, A. Velty, L. L. Santos, A. Leyva-Pérez, M. J. Sabater, S. Iborra and A. Corma, J. Catal., 2010, 271, 351.

20 See, for example: (a) T. Coleman and A. Blankenship, PCT Int. Appl., 2010, WO 2010/022263; (b) Ger. Off., 1998, DE19648960 (BASF AG).

21 See, for example: (a) J. M. Fraile, R. Mallada, J. A. Mayoral, M. Menéndez and L. Roldán, Chem.-Eur. J., 2010, 16, 3296; (b) G. Vicente, J. A. Melero, G. Morales, M. Paniagua and E. Martín, Green Chem., 2010, 12, 899; (c) H. García, J. I. García, J. M. Fraile and J. A. Mayoral, Focus on Catalysis Applications (Supplement to Chimica Oggi vol. 26, no. 3), 2008, pp. $10-12$.

22 For a recent review on this topic, see: B. Schäffner, F. Schäffner, S. P. Verevkin and A. Börner, Chem. Rev., 2010, 110, 4554.

23 See, for example: (a) C. Vieville, J. W. Yoo, S. Pelet and M. Mouloungui, Catal. Lett., 1998, 56, 245; (b) M. Aresta, A. Dibenedetto, F. Nocito and C. Pastore, J. Mol. Catal. A Chem., 2006, 257, 149; (c) J. George, Y. Patel, S. M. Pillai and M. Munshi, J. Mol. Catal. A: Chem., 2009, 304, 1. 
24 J. Hu, J. Li, Y. Gu, Z. Guan, W. Mo, Y. Ni, T. Li and G. Li, Appl. Catal., A, 2010, 386, 188.

25 See, for example: (a) G. Rokicki, P. Rakoczy, P. Parzuchowski and M. Sobieki, Green Chem., 2005, 7, 529; (b) S. C. Kim, Y. H. Kim, H. Lee, D. Y. Yoon and B. K. Song, J. Mol. Catal. B: Enzym., 2007, 49, 75; (c) K. S. Jung, J. H. Kim, J. H. Cho, D. K. Kim, PCT Int. Appl., 2009, WO 2009/035269.

26 A. Behr, P. Bahke, B. Klinger and M. Becker, J. Mol. Catal. A: Chem., 2007, 267, 149.

27 See, for example: (a) Handbook of Green Chemistry (Volume 6: Ionic Liquids), ed. P. Wasserscheid and A. Stark, Wiley-VCH, Weinheim, 2010; (b) Ionic Liquids in Synthesis, ed. P. Wasserscheid and T. Welton, Wiley-VCH, Weinheim, 2008; (c) Ionic Liquids in Organic Synthesis, ed. S. V. Malhotra, ACS Symposium Series, Washington, 2007; (d) P. J. Dyson and T. J. Geldbach, Metal Catalysed Reactions in Ionic Liquids, Springer, Dordrecht, 2005.

28 See, for example: (a) P. J. Scammells, J. L. Scott and R. D. Singer, Aust. J. Chem., 2005, 58, 155; (b) S. Zhu, R. Chen, Y. Wu, Q. Chen, X. Zhang and Z. Yub, Chem. Biochem. Eng. Q., 2009, 23, 207; (c) D. Coleman and N. Gathergood, Chem. Soc. Rev., 2010, 39, 600; $(d)$ T. P. Thuy Pham, C.-W. Cho and Y.-S. Yun, Water Res., 2010, 44, 352; (e) R. F. M. Frade and C. A. M. Afonso, Hum. Exp. Toxicol., 2010, 29, 1038.

29 A. Ten Kate, M. J. J. Mayer, C. J. G. Van Strien, B. Kuzmanovic and C. A. M. C. Dirix, PCT Int. Appl., 2008, WO 2008/074733.

30 F. Bellina, A. Bertoli, B. Melai, F. Scalesse, F. Signori and C. Chiappe, Green Chem., 2009, 11, 622.

31 C. Chiappe, F. Signori, G. Valentini, L. Marchetti, C. S. Pomelli and F. Bellina, J. Phys. Chem. B, 2010, 114, 5082.

32 See, for example: (a) A. P. Abbott, G. Capper, D. L. Davies, R. K. Rasheed and V. Tambyrajah, Chem. Commun., 2003, 70; (b) A. P. Abbott, D. Boothby, G. Capper, D. L. Davies and R. K. Rasheed, J. Am. Chem. Soc., 2004, 126, 9142.

33 See, for example: J. Zhang, T. Wu, S. Chen, P. Feng and X. Bu, Angew. Chem., Int.Ed., 2009, 48, 3486.

34 A. P. Abbott, P. M. Cullis, M. J. Gibson, R. C. Harris and E. Raven, Green Chem., 2007, 9, 868.

35 A. P. Abbott, R. C. Harris, K. S. Ryder, C. D'Agostino, L. F. Gladden and M. D. Mantle, Green Chem., 2011, 13, 82.

36 (a) C. Reichardt, Chem. Rev., 1994, 94, 2319; (b) C. Reichardt, Solvents and Solvent Effects in Organic Chemistry, Wiley-VCH, Weinheim, 2003.

37 For recent examples, see: (a) B. Singh, H. Lobo and G. Shankarling, Catal. Lett., 2011, 141, 178; (b) S. B. Phadtare and G. S. Shankarling, Green Chem., 2010, 12, 458; (c) Z. Chen, W. Zhu, Z. Zheng and X. Zuo, J. Fluorine Chem., 2010, 131, 340; (d) Y. A. Sonawane, S. B. Phadtare, B. N. Borse, A. R. Jagtap and G. Shankarling, Org. Lett., 2010, 12, 1456.

38 A. Wolfson, C. Dlugy and Y. Shotland, Environ. Chem. Lett., $2007,5,67$.

39 A. Wolfson and C. Dlugy, Org. Commun., 2009, 2, 34.

40 Y. Gu, J. Barrault and F. Jérôme, Adv. Synth. Catal., 2008, 350, 2007.

41 It should be noted that, although these catalyst-free Michael reactions of indoles can be conveniently performed in water, a slightly higher temperature $\left(100{ }^{\circ} \mathrm{C}\right)$ is required to attain similar conversions: P. M. Habib, V. Kabala, C.-W. Kuo and C.-F. Yao, Tetrahedron Lett., 2008, 49, 7005.

42 A. Wolfson, G. Litvak, C. Dlugy, Y. Shotland and D. Tavor, Ind. Crops Prod., 2009, 30, 78.

43 E. J. Lenardão, D. O. Trecha, P. C. Ferreira, R. G. Jacob and G. Perin, J. Braz. Chem. Soc., 2009, $20,93$.

44 F. He, P. Li, Y. Gu and G. Li, Green Chem., 2009, 11, 1767.

45 Related coupling reactions have been described using the Lewis acid $\mathrm{CeCl}_{3} \cdot 7 \mathrm{H}_{2} \mathrm{O}$ as a catalyst $(10 \mathrm{~mol} \%)$ in glycerol. In general, comparable yields in similar reaction times were obtained by working at $75{ }^{\circ} \mathrm{C}$. Remarkably, good results were also obtained starting from the poorly activated substrate 6-bromoindole. C. C. Silveira, S. R. Mendes, F. M. Líbero, E. J. Lenardão and G. Perin, Tetrahedron Lett., 2009, 50, 6060 .

46 (a) P. J. Kocienski, Protecting Groups, Thieme Verlag, Stuttgart, 3rd edn, 2003; (b) T. W. Greene and P. G. M. Wuts, Protective Groups in Organic Synthesis, Wiley-Interscience, New York, 3rd edn, 1999.
47 G. Perin, L. G. Mello, C. S. Radatz, L. Savegnago, D. Alves, R. G. Jacob and E. J. Lenardão, Tetrahedron Lett., 2010, 51, 4354.

48 See, for example: Multicomponent Reactions, ed. J. Zhu and H. Bienaymé, Wiley-VCH, Weinheim, 2005.

49 M. Li, C. Chen, F. He and Y. Gu, Adv. Synth. Catal., 2010, 352, 519.

50 J.-N. Tan, M. Li and Y. Gu, Green Chem., 2010, 12, 908.

51 A. Karam, N. Villandier, M. Delample, C. K. Koerkamp, J.-P. Douliez, R. Granet, P. Krausz, J. Barrault and F. Jérôme, Chem.-Eur. J., 2008, 14, 10196.

52 S. Balieu, A. El Zein, R. De Sousa, F. Jérôme, A. Tatibouët, S. Gatard, Y. Pouilloux, J. Barrault, P. Rollin and S. Bouquillon, Adv. Synth. Catal., 2010, 352, 1826.

53 D. Alves, M. Sachini, R. G. Jacob, E. J. Lenardão, M. E. Contreira, L. Savegnago and G. Perin, Tetrahedron Lett., 2011, 52, 133.

54 E. J. Lenardão, M. S. Silva, M. Sachini, R. G. Lara, R. G. Jacob and G. Perin, ARKIVOC, 2009, 11, 221.

55 (a) C. Estévez, N. Bayarri, J. Castells and B. Echeverría, PCT Int. Appl., 2008, WO 2008/080601; (b) C. Estévez, in Sustainable Solutions for Modern Economies, ed. R. Höfer, RSC Publishing, Cambridge, 2009, pp. 407-424.

56 H. García-Marín, J. C. van der Toorn, J. A. Mayoral, J. I. García and I. W. C. E. Arends, Green Chem., 2009, 11, 1605.

57 H. García-Marín, J. C. van der Toorn, J. A. Mayoral, J. I. García and I. W. C. E. Arends, J. Mol. Catal. A: Chem., 2011, 334, 83.

58 See, for example: (a) S. Murugesan and R. J. Linhardt, Curr. Org. Synth., 2005, 2, 437; (b) O. A. El Seoud, A. Koschella, L. C. Fidale, S. Dorn and T. Heinze, Biomacromolecules, 2007, 8, 2629; (c) V. Prasad, R. R. Kale, V. Kumar and V. K. Tiwari, Curr. Org. Synth., 2010, 7, 506.

59 See, for example: (a) X. Tong, Y. Ma and Y. Li, Appl. Catal., A, 2010, 385, 1; (b) K. D. O. Vigier and F. Jérôme, Top. Curr. Chem., $2010,295,63$.

60 M. Benoit, Y. Brissonnet, E. Guélou, K. D. O. Vigier, J. Barrault and F. Jérôme, ChemSusChem, 2010, 3, 1304.

61 A. Wolfson, D. Saidkarimov, C. Dlugy and D. Tavor, Green Chem. Lett. Rev., 2009, 2, 107.

62 (a) K. Tarama and T. Funabiki, Bull. Chem. Soc. Jpn., 1968, 41, 1744; (b) T. Funabiki and K. Tarama, Bull. Chem. Soc. Jpn., $1971,44,945$.

63 A. Wolfson and C. Dlugy, Chem. Pap., 2007, 61, 228.

64 See, for example: (a) S. B. Park and H. Halper, Org. Lett., 2003, 5, 3209; (b) G. Zou, W. Huang, Y. Xiao and J. Tang, New J. Chem., 2006, 30, 803.

65 M. Delample, N. Villandier, J.-P. Douliez, S. Camy, J.-S. Condoret, Y. Pouilloux, J. Barrault and F. Jérôme, Green Chem., 2010, 12, 804.

66 L. Botella and C. Najera, J. Org. Chem., 2005, 70, 4360.

67 For a recent review on this topic, see: S. P. Nolan and H. Clavier, Chem. Soc. Rev., 2010, 39, 3305.

68 D. Burtscher and K. Grela, Angew. Chem., Int. Ed., 2009, 48, 442, and references cited therein.

69 N. Bakhrou, F. Lamaty, J. Martinez and E. Colacino, Tetrahedron Lett., 2010, 51, 3935.

70 See, for example: A. Behr and G. Henze, Green Chem., 2011, 13, 25, and references cited therein.

71 Poor results, in terms of both activity and selectivity, were also observed in the partial hydrogenation of benzene into cyclohexene employing silica-supported ruthenium nanoparticles as catalysts in $\mathrm{H}_{2} \mathrm{O}$ /glycerol and $\mathrm{H}_{2} \mathrm{O}$ /triacetin solvent mixtures: E. V. Spinacé and J. M. Vaz, Catal. Commun., 2003, 4, 91.

72 L. Aldea, J. M. Fraile, H. García-Marín, J. I. García, C. I. Herrerías, J. A. Mayoral and I. Pérez, Green Chem., 2010, 12, 435 .

73 See, for example: (a) J. S. M. Samec, J.-E. Bäckvall, P. G. Andersson and P. Brandt, Chem. Soc. Rev., 2006, 35, 237; (b) T. Ikariya and A. J. Blacker, Acc. Chem. Res., 2007, 40, 1300.

74 According to the relative oxidation potentials of secondary $v s$. primary alcohols, oxidation is expected to selectively occur at the secondary hydroxyl group: H. Adkins, R. M. Elofson, A. G. Rossow and C. C. Robinson, J. Am. Chem. Soc., 1949, 71, 3622 . 
75 Dihydroxyacetone is used as a component in artificial tanning preparations in the cosmetic industry and as a valuable intermediate in biodegradable polymers synthesis. See, for example: K. Miltenberger, in Ullman's Encyclopedia Industrial Chemistry, ed. B. Elvers, S. Hawkins, M. Ravenscroft, J. F. Rounsaville and G. Schulz, Wiley-VCH, Weinheim, 1989, vol. A13, p. 507.

76 E. Farnetti, J. Kašpar and C. Crotti, Green Chem., 2009, 11, 704.

77 (a) C. Bianchini, E. Farnetti, M. Graziani, G. Nardin, A. Vacca and F. Zanobini, J. Am. Chem. Soc., 1990, 112, 9190; (b) E. Farnetti, N. V. Gulati and M. Graziani, Gazz. Chim. Ital., 1993, 123, 165.

78 C. Crotti, J. Kašpar and E. Farnetti, Green Chem., 2010, 12, 1295.

79 (a) A. Wolfson, C. Dlugy, Y. Shotland and D. Tavor, Tetrahedron Lett., 2009, 50, 5951; (b) D. Tavor, O. Sheviev, C. Dlugy and A. Wolfson, Can. J. Chem., 2010, 88, 305.

80 D. Tavor, S. Popov, C. Dlugy and A. Wolfson, Org. Commun., 2010, 3, 70.

81 (a) Y. Shi, W. Dayoub, A. Favre-Réguillon, G.-R. Chen and M. Lemaire, Tetrahedron Lett., 2009, 50, 6891; (b) Y. Shi, W. Daoub, G.-C. Chen and M. Lemaire, Green Chem., 2010, 12, 2189.

82 See, for example: (a) M. J. Climent, A. Corma and A. Veltry, Appl. Catal., A, 2004, 263, 155; (b) G. Hillion, B. Delfort and I. Durand, PCT Int. Appl., 2005, WO 2005/093015.

83 C. Crotti, E. Farnetti and N. Guidolin, Green Chem., 2010, 12, 2225.

84 For recent reviews on the synthesis of furans, see: $(a)$ S. F. Kirsch, Org. Biomol. Chem., 2006, 4, 2076; (b) D. M. D'Souza and T. J. J. Müller, Chem. Soc. Rev., 2007, 36, 1095; (c) G. Balme, D. Bouyssi and N. Monteiro, Heterocycles, 2007, 73, 87; (d) V. Cadierno and P. Crochet, Curr. Org. Synth., 2008, 5, 343.

85 (a) I. Özdemir, B. Yiğit, B. Çetinkaya, D. Ülkü, M. N. Tahir and C. Aric1, J. Organomet. Chem., 2001, 633, 27; (b) A. E. DíazÁlvarez, P. Crochet, M. Zablocka, C. Duhayon, V. Cadierno, J. Gimeno and J. P. Majoral, Adv. Synth. Catal., 2006, 348, 1671; (c) S. E. García-Garrido, J. Francos, V. Cadierno, J.-M. Basset and V. Polshettiwar, ChemSusChem, 2011, 4, 104.

86 J. Francos and V. Cadierno, Green Chem., 2010, 12, 1552.

87 B. Lastra-Barreira, J. Francos, P. Crochet and V. Cadierno, Green Chem., 2011, 13, 307.

88 L. C. Gonçaves, G. F. Fiss, G. Perin, D. Alves, R. G. Jacob and E. J. Lenardão, Tetrahedron Lett., 2010, 51, 6772.
89 See, for example: A. Debache, W. Ghalem, R. Boulcina, A. Belfaitah, S. Rhouati and B. Carboni, Tetrahedron Lett., 2009, 50, 5248, and references cited therein.

90 A. V. Narsaiah and B. Nagaiah, Asian J. Chem., 2010, 22, 8099.

91 See, for example: (a) D. J. Pollard and J. M. Woodley, Trends Biotechnol., 2007, 25, 66; (b) N. Ran, L. Zhao, Z. Chen and J. Tao, Green Chem., 2008, 10, 361; (c) Modern Biocatalysis: Stereoselective and Environmentally Friendly Reactions, ed. W.-D. Fessner and T. Anthonsen, Wiley-VCH, Weinheim, 2009; (d) M. J. Hernáiz, A. R. Alcántara, J. I. García and J. V. Sinisterra, Chem.-Eur. J., 2010, 16, 9422.

92 See, for example: (a) G. R. Castro and T. Knubovets, Crit. Rev. Biotechnol., 2003, 23, 195; (b) S. Torres and G. R. Castro, Food Technol. Biotechnol., 2004, 42, 271.

93 A. Wolfson, C. Dugly, D. Tavor, J. Blumenfeld and Y. Shotland, Tetrahedron: Asymmetry, 2006, 17, 2043.

94 The baker's yeast catalyzed asymmetric reduction of methyl acetoacetate using different glycerol/water mixtures was studied in more detail by Wolfson's group, which also evaluated the effect of glycerol on yeast viability and enzymatic activity. Increasing the glycerol content up to $50 \mathrm{wt} \%$ in water did not affect negatively the effectiveness of the process and allowed an easier and more efficient product extraction: A. Wolfson, N. Haddad, C. Dlugy, D. Tavor and Y. Shotland, Org. Commun., 2008, 1, 9.

95 L. H. Andrade, L. Piovan and M. D. Pasquini, Tetrahedron: Asymmetry, 2009, 20, 1521

96 S. S. Yoo, S. Park and E. Y. Lee, Biotechnol. Lett., 2008, 30, 1807.

97 C. Dlugy and A. Wolfson, Bioprocess Biosyst. Eng., 2007, 30, 327.

98 A. Wolfson, A. Atyya, C. Dlugy and D. Tavor, Bioprocess Biosyst. Eng., 2010, 33, 363.

99 (a) J. Gorke, F. Srienc and R. Kazlauskas, Biotechnol. Bioprocess Eng., 2010, 15, 40; (b) H. Zhao, J. Chem. Technol. Biotechnol., $2010,85,891$.

100 (a) J. T. Gorke, F. Srienc and R. J. Kazlauskas, Chem. Commun., 2008, 1235; (b) J. T. Gorke, R. J. Kazlauskas and F. Srienc, U.S. Pat. Appl. US2009/0117628, 2009; (c) J. T. Gorke, F. Srienc and R. J. Kazlauskas, in Ionic Liquid Applications: Pharmaceuticals Therapeutics and Biotechnology, (ACS Symposium Series vol. 1038), ed. S. V. Malhotra, American Chemical Society, Washington, 2010, pp. 169-180.

101 D. Lindberg, M. de la Fuente Revenga and M. Widersten, J. Biotechnol., 2010, 147, 169. 